Arkivoc

Free to Authors and Readers
A Platinum Open Access Journal for Organic Chemistry

Review
Arkivoc 2021, part vii, 12-47

\title{
Hypervalent iodine chemistry and light: photochemical reactions involving hypervalent iodine Chemistry
}

\author{
Fateh V. Singh ${ }^{a *}$ and Thomas Wirth ${ }^{b *}$ \\ ${ }^{a}$ Chemistry Division, School of Advanced Science, Vellore Institute of Technology (VIT) Chennai, Chennai- \\ 600 127, Tamil Nadu, India \\ ${ }^{b}$ School of Chemistry, Cardiff University, Park Place, Main Building, Cardiff CF10 3AT (United Kingdom) \\ Email:wirtht@cardiff.ac.uk; fatehveer.singh@vit.ac.in
}

Received 01-31-2021

Accepted 04-26-2021

Published on line $05-12-2021$

\begin{abstract}
Chemistry of hypervalent iodine reagents have developed extensively after the discovery of IBX as a commercial reagent in organic synthesis. Their stability in air, environmentally nature and unique reactivity under mild reaction conditions makes them more suitable reagents for medicinal and natural product chemistry. Various synthetic transformations have been achieved by using hypervalent iodine reagents under mild reaction conditions. Hypervalent iodine catalysis is identified as an emerging research area in past couple of decades. In past few years, hypervalent iodine reagents have found their application in photoredox catalysis. In this review article, the progress of photoredox catalysis by involving hypervalent iodine reagents would be covered.
\end{abstract}

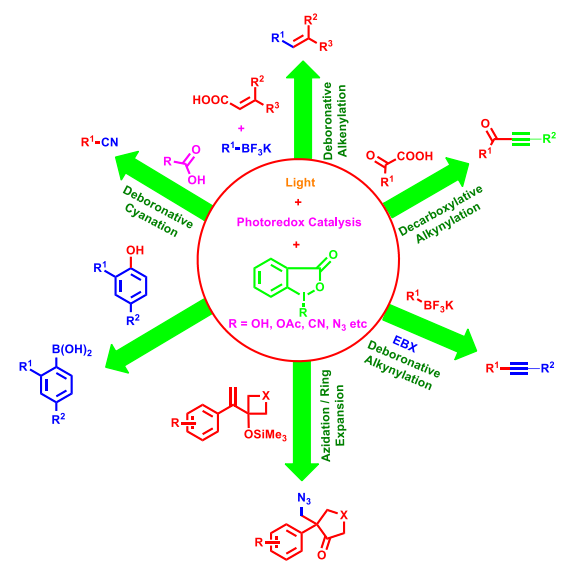

Keywords: Hypervalent iodine, photoredox, photocatalyst, LED, irradiation, photoexcited 


\section{Table of Contents}

1. Introduction

2. Photochemical Reactions with Photoredox Catalysis

2.1. Alkynylation

2.1.1. Deboronative alkynylation

2.1.2. Decarboxylative alkynylation

2.1.3. Alkynylation of aldehydes

2.1.4. Alkynylation of alcohols with bond cleavage

2.1.5. Alkynylation of cyclic oxime ethers

2.1.6. Amidoalkynylation of unactivated alkenes

2.2. Alkenylation

2.3. Cyanation reactions

2.4. C-H Alkylation reactions

2.5. Arylation reactions

2.6. C-H Diazomethylation of arenes

2.7. Azidation reactions

2.8. Conversion of arylboronic acids to phenols

3. Photochemical reactions without photoredox catalysis

3.1. Aminocyclization reactions

3.2. Decarboxylative acylarylation

3.3. Cyclopropanation reaction

4. Conclusion

5. Acknowledgements

References

\section{Introduction}

In the past few decades, the chemistry of hypervalent iodine reagents has contributed significantly to organic synthesis and natural product chemistry. ${ }^{1-4}$ These reagents are known to achieve various oxidative transformations under mild and environment friendly reaction conditions. ${ }^{5-17}$ Several hypervalent iodine reagents have been identified as potential oxidants. ${ }^{18-23}$ Additionally, these reagents have been successfully applied to obtain several synthetic transformations including cyclizations, ${ }^{24-30}$ aminations, ${ }^{31-34} \alpha-$ functionalizations of carbonyl compounds, ${ }^{35-38}$ arylations, ${ }^{39-41}$ atom-transfer reactions, ${ }^{42}$ cycloaddition reactions, ${ }^{43-45}$ and oxidative rearrangements. ${ }^{46-49}$ Moreover, these reagents have been used as catalyst to develop number of organic transformations. ${ }^{50-54}$ In recent years, hypervalent iodine reagents received a particular attention in visible-light photoredox catalysis. ${ }^{55}$ In this review article, the visible-light photoredox reactions are covered where the hypervalent iodine reagents are involved. 


\section{Photochemical Reactions with Photoredox Catalysis}

\subsection{Alkynylation}

Alkynylation is an important reaction in synthetic organic chemistry and there are various routes available to achieve the alkynylation reactions in literature. ${ }^{56}$ In past decade, ethynylbenziodoxole (EBX) has been introduced successfully for the alkynylation of different organic species. ${ }^{57-59}$ Recently, alkynylation of different organic species has been successfully achieved by using the combination of hypervalent iodine reagents with various photoredox catalysts. Mainly, cyclic hypervalent iodine reagents have been used in photoredox catalysis and their role is to generate the radical species. In this section, various photo-catalyzed alkynylation of various organic compounds using hypervalent iodine reagents would be highlighted.

2.1.1. Deboronative alkynylation. In 2014, the deboronative alkynylation of potassium alkyl trifluoroborates was reported by using ruthenium complex $\mathbf{4}$ as photo-catalyst in the presence of blue light. This was the first photo-catalyzed radical alkynylation approach by using EBX (ethynylbenziodoxole) $\mathbf{2}$ as source of alkynic species. In all the reactions, blue light was used to driven the photoredox and 1,3-disubstituted alkynes 5 were isolated in good to high yields (Scheme 1). ${ }^{60}$ The combination of $\mathrm{BI}-\mathrm{OH}$ (hydroxybenziodoxole) 3 (5.0 mol \%) and photo-catalyst $\mathrm{Ru}(\mathrm{bpy})_{3}\left(\mathrm{PF}_{6}\right)_{2} 4(2.0 \mathrm{~mol} \%)$ was used as catalytic system. Interestingly, various functional groups were successfully tolerated under given reaction conditions and reaction products were obtained in good yields without detecting in side reactions.

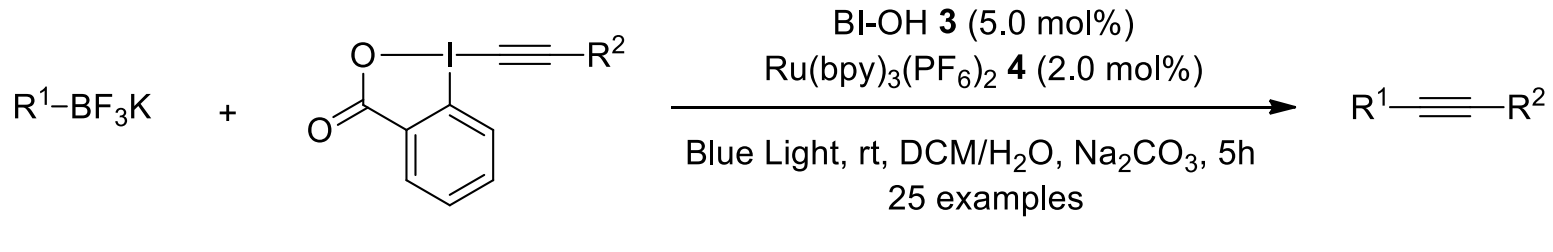

1

2

5: $59-85 \%$

$\mathrm{R}^{1}=1$-Indenyl, $\mathrm{Cy}, \mathrm{Ph}, \mathrm{Bn}, 4-\mathrm{BrC}_{4} \mathrm{H}_{4}$ etc; $\mathrm{R}^{2}=\mathrm{Ph}, 4-\mathrm{ClC}_{4} \mathrm{H}_{4}, 4-$

$\mathrm{PhC}_{4} \mathrm{H}_{4}, 4-\mathrm{MeC}_{4} \mathrm{H}_{4}, 4-\mathrm{CHOC}_{4} \mathrm{H}_{4}, 4-\mathrm{MeCOC}_{4} \mathrm{H}_{4}, 2-\mathrm{CNC}_{4} \mathrm{H}_{4}$ etc

Scheme 1. Photoredox-catalyzed deboronative alkynylation of potassium alkyl trifluoroborates 1 with alkynyl benziodoxole 2 to alkynes 5 .

The possible mechanism for the deboronative alkynylation of potassium alkyl trifluoroborates 1 with EBX 2 in the presence of photoredox catalyst 4 is described in scheme 2 . Initially, $\mathrm{Ru}(\mathrm{II})^{2+}$ absorbs the blue light and gets excited to $\mathrm{Ru}(\mathrm{II})^{2+*}$. The photo-excited ruthenium species is further oxidized to $\mathrm{Ru}(\mathrm{III})^{3+}$ probably either by benziodoxole radical or its precursor $\mathrm{BI}-\mathrm{OH}$ 3. Furthermore, $\mathrm{Ru}(\mathrm{III})^{3+}$ oxidized organotrifluoroborate species 1 to corresponding alkyl $R^{1}$ radical and regenerates $\mathrm{Ru}(\mathrm{II})_{3}{ }^{2+}$. Finally, alkyl $\mathrm{R}^{1}$ radical provides desired alkynes 5 on $\alpha$-addition to EBX. In this process, benziodoxole radical 6 eliminates which oxidize $\mathrm{Ru}(\mathrm{II})^{2+{ }^{*}}$ to $\mathrm{Ru}(\mathrm{III})^{3+}$ and form ortho-iodobenzoic acid. Furthermore, the $\mathrm{Ru}(\mathrm{III})^{2+}$ enters into the next catalytic cycle. 


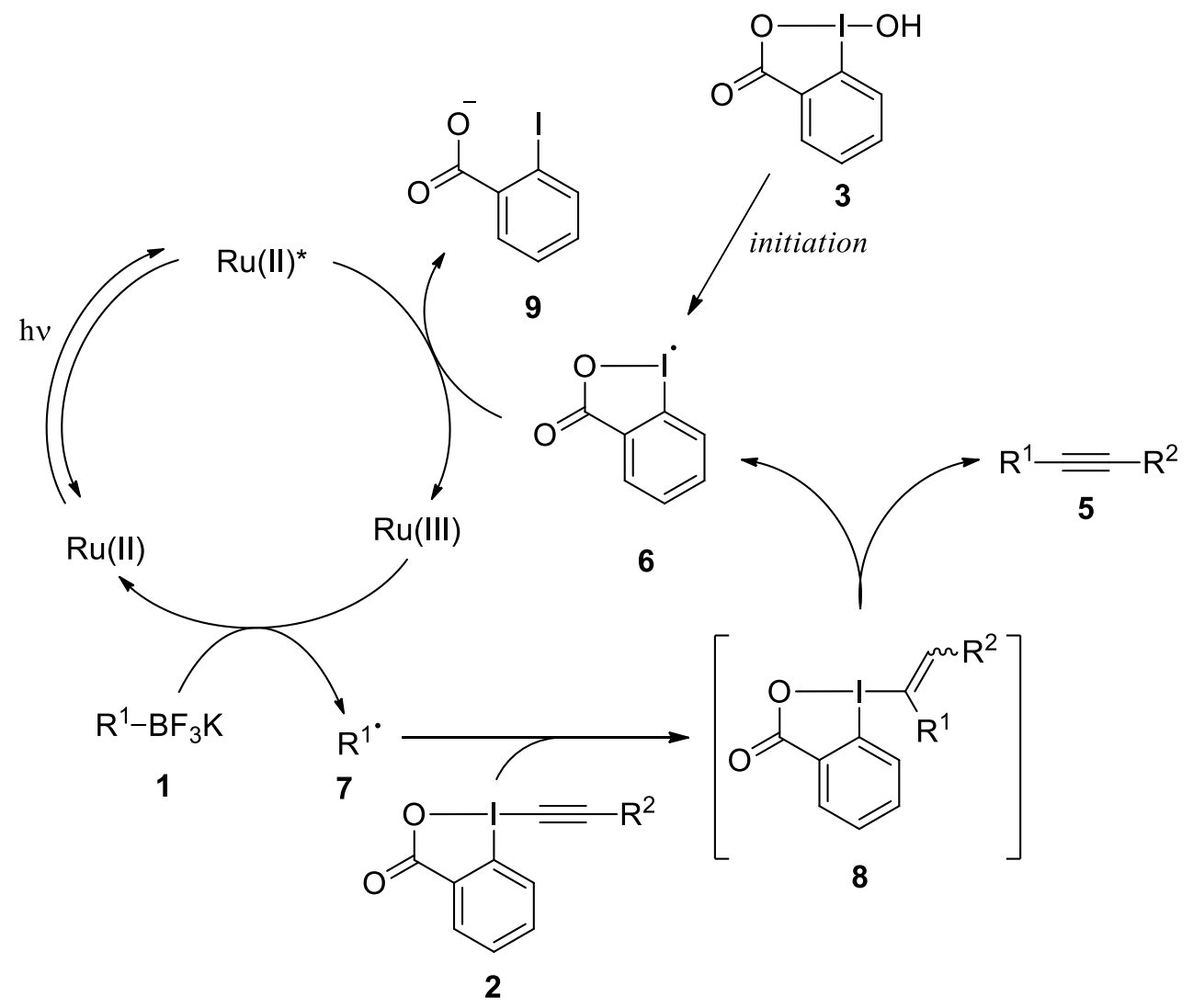

Scheme 2. Mechanism for the photoredox-catalyzed deboronative alkynylation of potassium alkyl trifluoroborates 1 with alkynyl benziodoxole 2 to alkynes 5 .

2.1.2. Decarboxylative alkynylation. Synthetic application of hypervalent iodine reagents in photoredox reactions were further explored in decarboxylative alkynylation reactions by different research groups. The same photoredox catalyst 4 was applied to develop decarboxylative ynonylation under mild reaction conditions. ${ }^{61} \alpha$-Keto acids 10 were treated with alkynyl benziodoxoles 2 using BI-OAc (acetoxybenziodoxole) 11 as an additive and ruthenium species 4 as photoredox catalyst in the presence of blue light at $468 \mathrm{~nm}$. The ynonylation reactions were proceeded well and functionalized ynones $\mathbf{1 2}$ were obtained in good to high yields (Scheme 3). Wide range of functional groups sensitive to the transitional metal catalysis were successfully tolerated under the conditions summarized in scheme 3. The decarboxylative alkynylation follow the free radical mechanism. Aromatic $\alpha$-keto acids showed better yields in the decarboxylative alkynylation reactions compare to the aliphatic keto acids. Interestingly, the dual decarboxylative-decarbonylative alkyne coupling product was observed in case of tert-alkyl keto acids. 


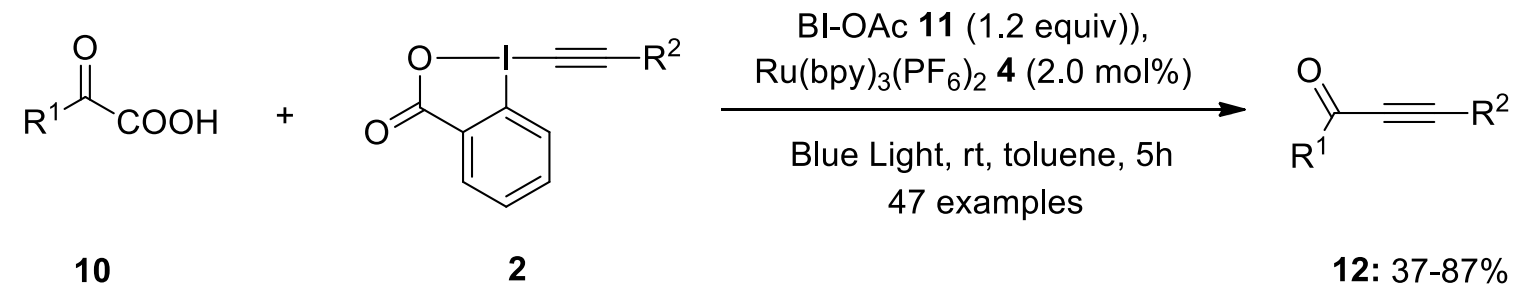

$\mathrm{R}^{1}=$ Aryl, Thienyl, furyl, $\mathrm{Cy}, \mathrm{Bn}, \mathrm{BnCH}_{2}, \mathrm{ArNH}, \mathrm{RNH}$,

$(\mathrm{R})_{2} \mathrm{NH}$, alkyl, OEt, etc; $\mathrm{R}^{2}=$ aryl, alkyl and TIPS etc.

Scheme 3. Photo-induced decarboxylative alkynylation of $\alpha$-ketoacids $\mathbf{1 0}$ with alkynyl benziodoxoles 2 to ynones 12.

$\alpha$-Ketoacids $\mathbf{1 0}$ were further employed in decarboxylative coupling with functionalized bromoacetylenes 13 using catalytic amount of $\mathrm{BI}-\mathrm{OH} \mathbf{3}$ in the presence of sunlight and functionalized ynones $\mathbf{1 2}$ were obtained in good yields (Scheme 4). ${ }^{62}$ Notably, these results were comparable with the results obtained by using blue light $(\lambda=450-455 \mathrm{~nm})$. Once again wide range of functional groups were studied during the progress of this reactions and bromoacetylenes functionalized with electron-donating groups showed poor yields compare to the electron-withdrawing groups. During the optimization studies, various organic and inorganic photoredox catalysts were also employed but showed poor yields.

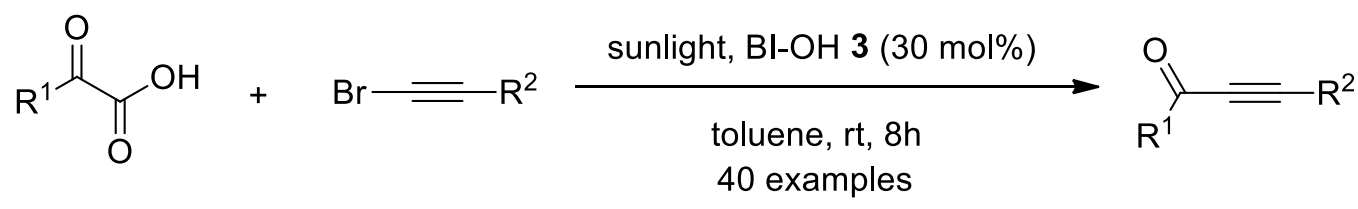

10

$$
\begin{aligned}
& \mathrm{R}^{1}=\mathrm{Ph}, 4-\mathrm{BrC}_{4} \mathrm{H}_{4}, 4-\mathrm{ClC}_{4} \mathrm{H}_{4}, 4-\mathrm{FC}_{4} \mathrm{H}_{4}, 4-\mathrm{MeC}_{4} \mathrm{H}_{4}, 4-\mathrm{OMeC}_{4} \mathrm{H}_{4}, 2- \\
& \mathrm{BrC}_{4} \mathrm{H}_{4}, \quad 2-\mathrm{ClC}_{4} \mathrm{H}_{4}, 2-\mathrm{FC}_{4} \mathrm{H}_{4}, \quad 2-\mathrm{MeC}_{4} \mathrm{H}_{4}, 2-\mathrm{OMeC}_{4} \mathrm{H}_{4}, 2,4- \\
& \mathrm{Me}_{2} \mathrm{C}_{4} \mathrm{H}_{3}, 2,5-\mathrm{Me}_{2} \mathrm{C}_{4} \mathrm{H}_{3}, 3,4-(\mathrm{OMe})_{2} \mathrm{C}_{4} \mathrm{H}_{3} \text { etc; } \mathrm{R}^{2}=\mathrm{Ph}, 4-\mathrm{ClC}_{4} \mathrm{H}_{4} \\
& \text { 4- } \mathrm{BrC}_{4} \mathrm{H}_{4}, 4-\mathrm{FC}_{4} \mathrm{H}_{4}, 4-\mathrm{OMeC}_{4} \mathrm{H}_{4}, 3-\mathrm{MeC}_{4} \mathrm{H}_{4}, 2-\mathrm{BrC}_{4} \mathrm{H}_{4} \text { etc. }
\end{aligned}
$$

Scheme 4. Sunlight-driven decarboxylative coupling of $\alpha$-ketoacids 10 with bromoacetylenes 13 to ynones 12.

The mechanism for sunlight-driven decarboxylative coupling is summarized in scheme 5 . The reaction was initiated with reaction of $\mathrm{BI}-\mathrm{OH} 3$ with $\alpha$-keto acid 10 to form the intermediate $\mathbf{1 4}$. lodine-oxygen bond of intermediate $\mathbf{1 4}$ cleaved in the presence of sunlight and generates the iodanyl radical $\mathbf{1 5}$ and acyl radical 17. Furthermore, the iodanyl radical $\mathbf{1 5}$ reacts with bromoacetylene $\mathbf{1 3}$ to give alkynyl benziodoxole intermediate 18 along with the formation of bromine radical. On addition of intermediate 18 with acyl radical 17, another intermediate 19 formed which releases the coupling product 12 along with the regeneration of intermediate 15. Finally, iodanyl radical $\mathbf{1 5}$ reacts with bromine radical to form $\mathrm{BI}-\mathrm{Br}$ (bromobenziodoxole) $\mathbf{2 0}$ which undergoes hydrolysis to regenerate $\mathrm{BI}-\mathrm{OH}$ 3. The regenerated species 3 enters into next the catalytic cycle. 


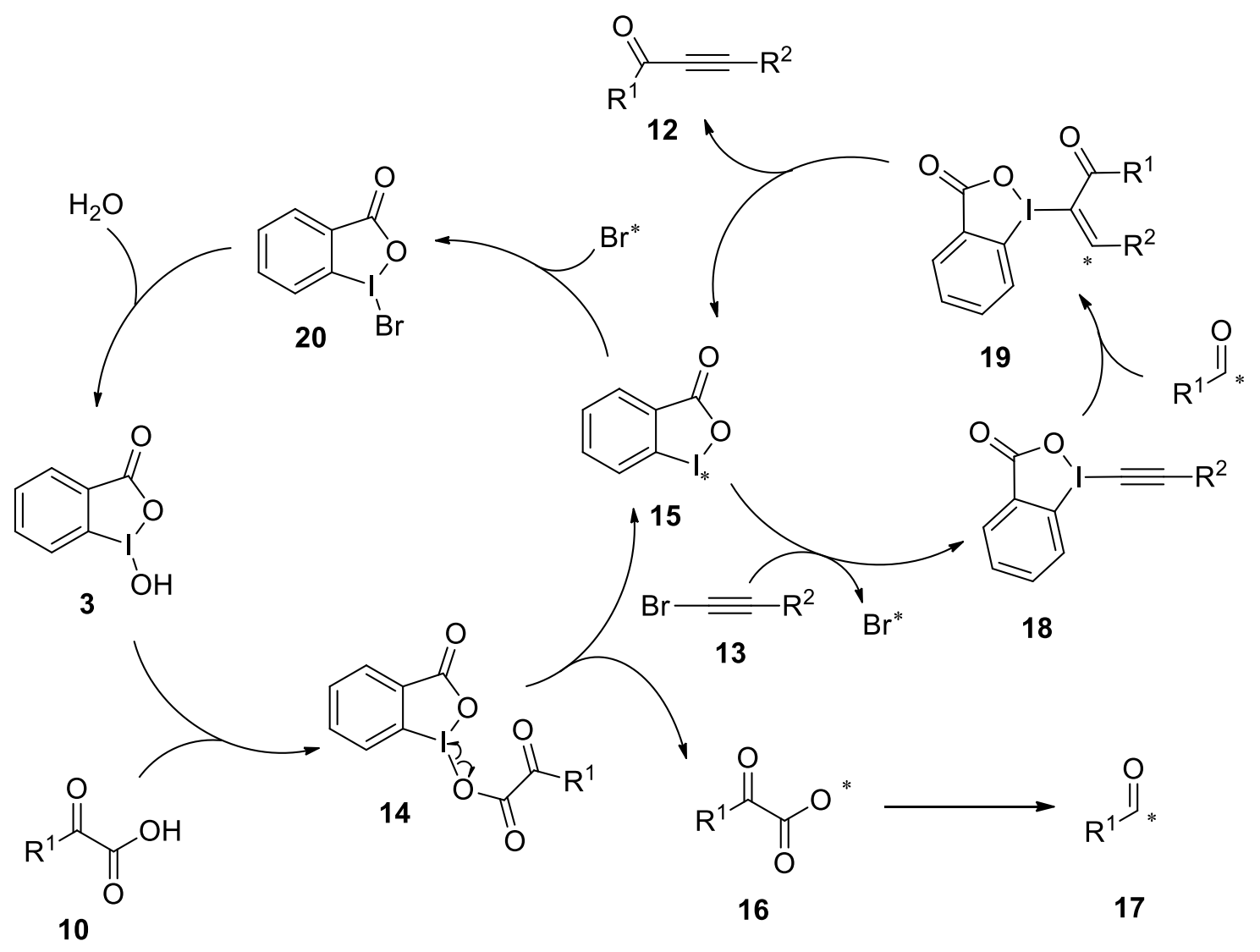

Scheme 5. Mechanism for the sunlight-driven decarboxylative coupling of $\alpha$-ketoacids 10 with bromoacetylenes 13 to ynones 12 .

In order to develop the decarboxylative alkynylation of carboxylic acids using photoredox catalysis, another report came in 2015 by Xiao and co-workers. ${ }^{63}$ In this report, iridium complex $\mathbf{2 1}$ was used as photocatalyst which was excited by blue light to generate the alkyl or cycloalkyl radical. Most of the coupling reactions proceeded well at room temperature in dichloromethane and 1,2-disubstituted acetylenes $\mathbf{5}$ were obtained in good to excellent yields (Scheme 6). Several carbocyclic carboxylic acids were successfully used as substrates during these coupling reactions but ynone based compounds were observed in case of benzoic and acetic acid. The course of the reaction was not much influenced by the presence of different aliphatic and aromatic groups in alkynyl benziodoxoles $\mathbf{2}$ and reaction products were isolated in excellent yields. 


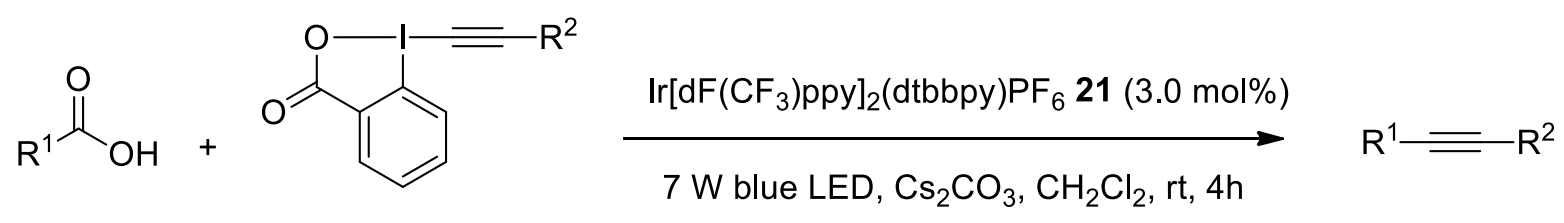

$\mathrm{R}^{1}=\mathrm{Me}, \mathrm{Ph}, \mathrm{Cy}$, admentyl, cyclopentyl etc; $\mathrm{R}^{2}=\mathrm{Ph}, 4-\mathrm{ClC}_{4} \mathrm{H}_{4}, 4-$

$\mathrm{PhC}_{4} \mathrm{H}_{4}, 4-\mathrm{FC}_{4} \mathrm{H}_{4}, 4-\mathrm{MeC}_{4} \mathrm{H}_{4}, 3,5-\mathrm{Me}_{2} \mathrm{C}_{4} \mathrm{H}_{3}$, pentyl, ${ }^{t} \mathrm{Bu}$ etc.

Scheme 6. Photo-catalytic decarboxylative alkynylation of carboxylic acids $\mathbf{2 0}$ with alkynyl benziodoxoles $\mathbf{2}$ to 1,2-disubstituted acetylenes 5.

Moreover, the same photocatalytic approach was used to develop decarboxylative carbonylative alkynylation of cyclic and acyclic carboxylic acids $\mathbf{2 0}$ with alkynyl benziodoxoles $\mathbf{2}$ in the presence of carbon monoxide (CO) under almost similar reaction conditions. Ynones 12 were afforded as reaction products in high yields (Scheme 7). Wide range of substrates scope and mild reaction conditions makes this approach for suitable for synthetic organic chemists. Like previous reports, the mechanism of the decarboxylative alkynylation and decarboxylative carbonylative alkynylation reactions followed the similar radical photoredox catalytic cycle.

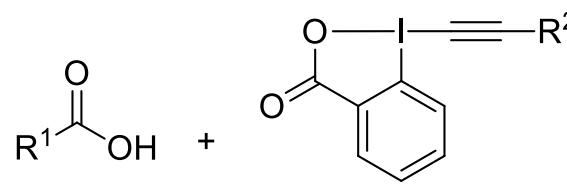

20
2

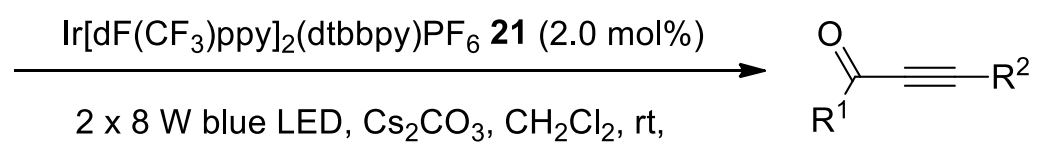

60 bar $\mathrm{CO}, 4 \mathrm{~h}$

15 examples

12: $42-90 \%$

$\mathrm{R}^{1}={ }^{i} \mathrm{Pr},{ }^{t} \mathrm{Bu}, \mathrm{Cy}$, cyclopentyl,

cyclobutyl, etc; $\mathrm{R}^{2}=\mathrm{Ph},{ }^{t} \mathrm{Bu}, \mathrm{Si}\left({ }^{i} \mathrm{Pr}\right)_{3}$

Scheme 7. Photocatalytic decarboxylative carbonylative alkynylation of carboxylic acids 20 with alkynyl benziodoxoles 2 to ynones 12 .

Furthermore, Waser and co-workers reported a more compact study on the decarboxylative alkynylation of carboxylic acids. ${ }^{64}$ In this study, various iridium and ruthenium based photo-catalysts were screened carefully and results obtained clearly the superiority of iridium catalyst over ruthenium in redox catalysis. This photoredox catalysis approach was advantageous over others due to low catalytic loading (up to 0.5 mol \%) and its success in case of $\alpha$-amino and $\alpha$-oxo acids derived from biomass. Recently, alkynyl sulfones have been identified as potential alternative of alkynyl benziodoxoles $\mathbf{2}$ in photocatalytic decarboxylative alkynylation reactions. ${ }^{65}$

In 2016, similar decarboxylative alkynylation of carboxylic acids were developed by replacing metal photoredox catalysts with organic photoredox catalyst. ${ }^{66}$ This approach was organophotocatalytic decarboxylative alkynylation of carboxylic acids with alkynyl benziodoxoles $\mathbf{2}$ and it was quite cost effective compare with other existing approaches. During these alkynylations, $5.0 \mathrm{~mol} \%$ of 9,10-dicyanoanthracene 
(DCA) was used as photocatalyst in the presence of base in the presence of blue light. The reaction products 24 were obtained in good to excellent yields and scope of the substrates were widely studied (Scheme 8). 9,10-Dicyanoanthracene (DCA) 23 is having high singlet excited-state oxidation potential which makes it more suitable as photoredox catalyst.

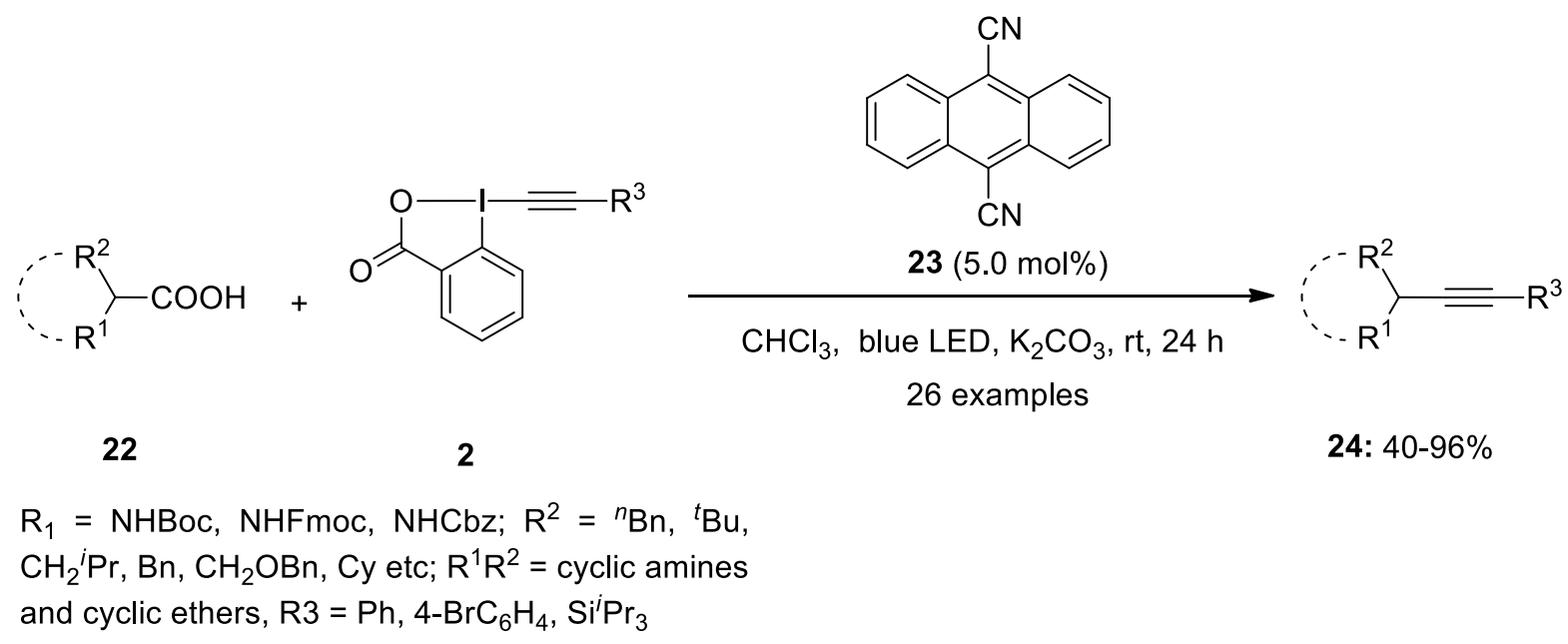

Scheme 8. Organophotocatalytic decarboxylative carbonylative alkynylation of carboxylic acids $\mathbf{2 2}$ with alkynyl benziodoxoles 2 to 1,2-disubstituted acetylenes 24 .

The mechanism for the organophotocatalytic decarboxylative carbonylative alkynylation of carboxylic acids $\mathbf{2 2}$ is summarized in scheme 9. Initially, the organic photoredox catalyst $\mathbf{2 3}$ absorbs the blue light and get excited which oxidizes the deprotonated acid 22. As a result the exited catalytic species get reduced along with the formation of carboxyl radical 25. Furthermore, the addition of carboxyl radical 25 to alkynyl benziodoxoles $\mathbf{2}$ would lead another unstable radical adduct $\mathbf{2 6}$. Finally, radical intermediate $\mathbf{2 6}$ undergo a $\beta$ elimination to give the desired product $\mathbf{2 4}$ along with the formation of benziodoxolonyl radical 27. Benziodoxolonyl radical $\mathbf{2 7}$ could be reduced to 2 -iodobenzoate $\mathbf{2 8}$ to complete the catalytic cycle. Additionally, the oxidation of deprotonated acid $\mathbf{2 2}$ to carboxyl radical $\mathbf{2 5}$ by 2 -iodobenzoate $\mathbf{2 8}$ would be other possibility to propagate the reaction. 


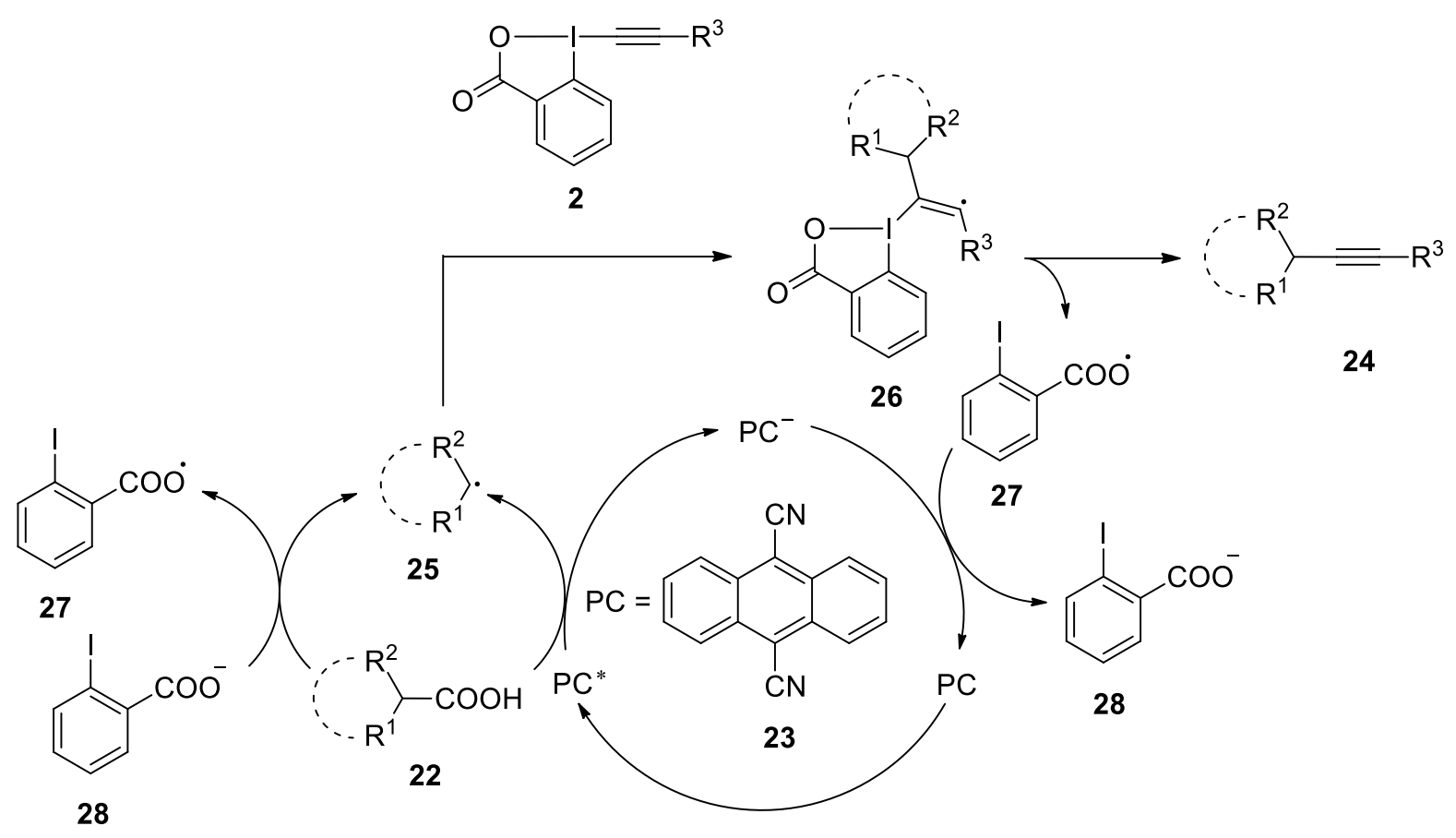

Scheme 9. Mechanism for organophotocatalytic decarboxylative carbonylative alkynylation of carboxylic acids 22 with alkynyl benziodoxoles 2 to 1,2-disubstituted acetylenes 24.

Recently, Waser and co-workers developed another photoorganocatalytic approach for the decarboxylative alkynylation of carboxylic acids. ${ }^{67}$ More importantly, the reported approach was successfully applied for the decarboxylative alkynylation of the C-terminus of peptides and hypervalent iodine species were used to introduce alkynylic functionality. Notably, the reaction showed a significant selectivity for the C-terminus despite in the presence of aspartic or glutamic acid residues.

2.1.3. Alkynylation of aldehydes. Furthermore, the photoredox catalysis was used for the alkynylation of aldehydes via hydrogen atom transfer process. ${ }^{68}$ In this approach, aldehydes 29 were treated with ethynylbenziodoxole (EBX) $\mathbf{2}$ by using catalytic combination sodium 2-iodobenzoate and BI-OAc $\mathbf{1 1}$ in the presence of iridium based photocatalyst $\mathbf{2 1}$ (Scheme 10). Blue LED (5 W) was used to activate the photocatalyst and ynones $\mathbf{1 2}$ were obtained in good yields. The scope of the substrates was widely explored and various sensitive functional groups were tolerated efficiently under given reaction conditions. Moreover, different amides and esters were also found the suitable substrates for these alkynylation reactions. In this reaction, the role of sodium 2-iodobenzoate is to quench the excited $\mid \mathrm{Ir}^{\mathrm{II}}$ to $\mathrm{Ir}$ "l and generation of 2iodobenzoyloxyl radical which could undergo hydrogen-atom abstraction to form the carbonyl radical of substrates. 


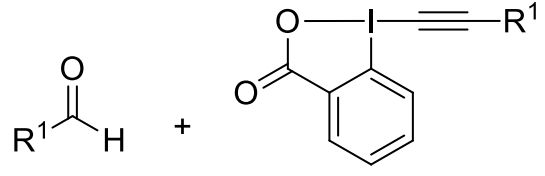

29

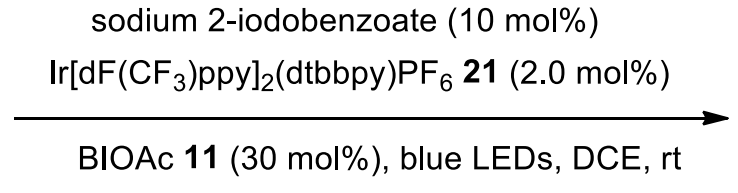

25 examples

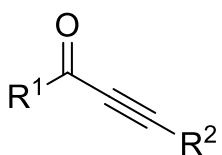

12: $59-90 \%$

$\mathrm{R}^{1}={ }^{i} \mathrm{Pr}, \mathrm{Bn}$, cyclopropyl, admentyl, $\mathrm{BnCH}_{2}, \mathrm{iPrCH}_{2}$, pentyl, 2-thienyl, $\mathrm{Ph}, \quad 4-\mathrm{ClC}_{6} \mathrm{H}_{4}, 4-\mathrm{MeC}_{6} \mathrm{H}_{4}$, 4$\mathrm{CF}_{3} \mathrm{C}_{6} \mathrm{H}_{4}$, PhO, piperidine, $\left({ }^{n} \mathrm{Bu}\right)_{2} \mathrm{~N}$ etc; $\mathrm{R}^{2}=\mathrm{Ph}, 4-$ $\mathrm{FC}_{6} \mathrm{H}_{4}, 4-\mathrm{CIC}_{6} \mathrm{H}_{4}, 4-\mathrm{MeC}_{6} \mathrm{H}_{4}, 3-\mathrm{OMeC}_{6} \mathrm{H}_{4}$, TIPS.

Scheme 10. Photoredox-catalyzed alkynylation of aldehydes 29 to ynones $\mathbf{1 2}$.

2.1.4. Alkynylation of alcohols with bond cleavage. In 2016, Chen and co-workers developed a visible-light induced $\mathrm{C}\left(\mathrm{sp}^{3}\right)-\mathrm{C}\left(\mathrm{sp}^{3}\right)$ bond cleavage followed by alkynylation. ${ }^{69}$ During these alkynylation reactions, cyclopropanols $\mathbf{3 0}$ were oxidized to generate alkoxyl radicals by cyclic hypervalent iodine reagents and undergo $\mathrm{C}\left(\mathrm{sp}^{3}\right)-\mathrm{C}\left(\mathrm{sp}^{3}\right)$ bond cleavage followed by alkynylations in one pot. This was the first report where alkoxyl radicals were successfully applied to achieve $\mathrm{C}\left(\mathrm{sp}^{3}\right)-\mathrm{C}\left(\mathrm{sp}^{3}\right)$ bond cleavage with alkynylation under photoredox conditions. The reactions proceeded at room temperature and reaction products 31 were obtained in good yields (Scheme 11). Additionally, the reaction showed good potential for the other strained cycloalkanols such as cyclobutanols. Interestingly, the scope of this approach was not limited to the strained cycloalkanols but also applicable for the linear alcohols as well.

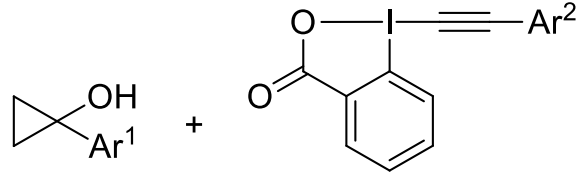

30

2

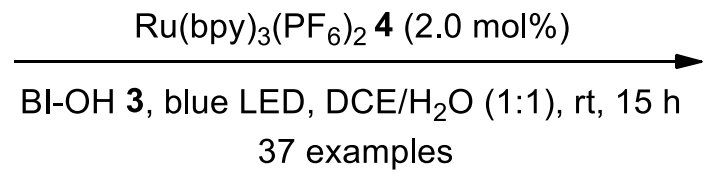

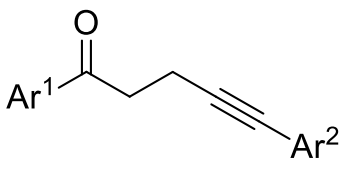

31: $46-86 \%$

$\mathrm{Ar}^{1}=\mathrm{Ph}, 4-\mathrm{ClC}_{6} \mathrm{H}_{4}, 4-\mathrm{BrC}_{6} \mathrm{H}_{4}, 4-\mathrm{FC}_{6} \mathrm{H}_{4}, 4-\mathrm{MeC}_{6} \mathrm{H}_{4}, 3-\mathrm{MeC}_{6} \mathrm{H}_{4}, 4-\mathrm{OMeC}_{6} \mathrm{H}_{4}$, 2-

furyl, $\mathrm{Bn}, \mathrm{CH}_{2} \mathrm{Bn}$ and $\mathrm{Cy}$ etc; $\mathrm{Ar}^{2}=\mathrm{Ph}, 4-\mathrm{ClC}_{6} \mathrm{H}_{4}, 4-\mathrm{BrC}_{6} \mathrm{H}_{4}, 4-\mathrm{FC}_{6} \mathrm{H}_{4}, 4-\mathrm{MeC}_{6} \mathrm{H}_{4}$,

$3-\mathrm{MeC}_{6} \mathrm{H}_{4}, 4-\mathrm{OMeC}_{6} \mathrm{H}_{4}, 4-\mathrm{MeCOC}_{6} \mathrm{H}_{4}, 4-\mathrm{CHOC}_{6} \mathrm{H}_{4}$ and 2- $\mathrm{CNC}_{6} \mathrm{H}_{4}$ etc.

Scheme 11. Photoredox-catalyzed alkynylation of cyclopropanols $\mathbf{3 0}$ to alkynylative adduct 31.

Furthermore, the photoredox catalysis was applied to develop another carbon-carbon bond cleavage/alkynylation approach by same research group using almost similar catalytic system. ${ }^{70}$ In this approach, selective carbonyl $\mathrm{C}\left(\mathrm{sp}^{3}\right)$ bond cleavage/alkynylation of $\beta$-carbonyl alcohols 31 was developed under mild reaction conditions and afforded ynones 12 in good yields (Scheme 12). Once again reaction was progressed with the formation of alkoxyl radicals but $\mathrm{BI}-\mathrm{OH} \mathbf{3}$ was not found successful to generate there radicals. Highly fluorinated $\mathrm{BI}-\mathrm{OH} 32$ showed great potential to generate alkoxyl radical of $\beta$-carbonyl alcohols 31 with high redox potential. The scope of this reaction was expanded to other $\beta$-carbonyl alcohols such as $\beta$ amide and $\beta$-ester alcohols to produce ynamides and ynoates respectively, in good yields. 


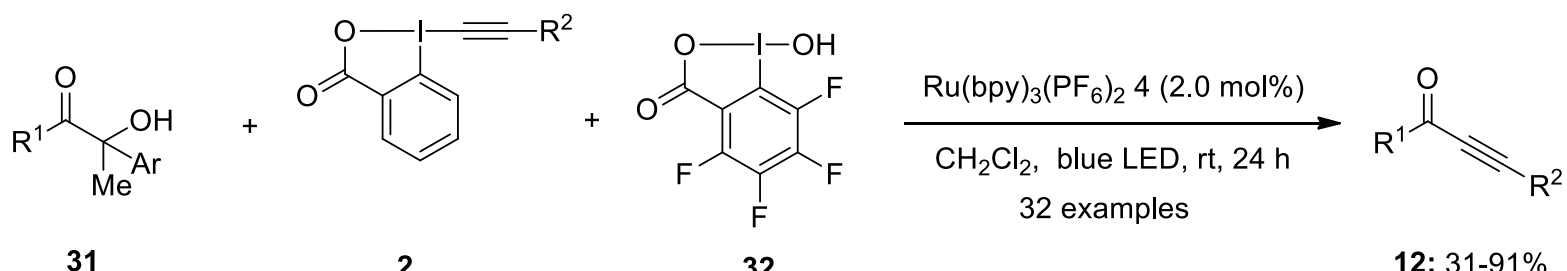

$\mathrm{R}^{1}=\mathrm{NHPh}, \mathrm{N}(\mathrm{Me})(\mathrm{Ph})$, piperidine, OEt, OBn, $\mathrm{O}^{t} \mathrm{Bu}$,

$\mathrm{Me}, \mathrm{Ph}, 3-\mathrm{MeC}_{6} \mathrm{H}_{4}, \quad 4-\mathrm{MeC}_{6} \mathrm{H}_{4}, 3-\mathrm{OMeC}_{6} \mathrm{H}_{4}$, 4-

$\mathrm{OMeC}_{6} \mathrm{H}_{4}$, 2-Nap etc; $\mathrm{R}^{2}={ }^{n} \mathrm{Hex}$, TIPS, 3-OMeC ${ }_{6} \mathrm{H}_{4}$,

4- $\mathrm{MeC}_{6} \mathrm{H}_{4}$, 4- $\mathrm{ClC}_{6} \mathrm{H}_{4}$, 4- $\mathrm{FC}_{6} \mathrm{H}_{4}$, 4- $\mathrm{MeCOC}_{6} \mathrm{H}_{4}$, 4-

$\mathrm{PhC}_{6} \mathrm{H}_{4}$ etc.

Scheme 12. Photoredox-catalyzed carbonyl-C(sp3)-bond cleavage/alkynylation of $\beta$-carbonyl alcohols 31 to ynones 12.

Moreover, the same research group reported a phosphorus- $\mathrm{C}\left(\mathrm{sp}^{3}\right)$ bond cleavage/alkynylation approach by using photoredox catalysis. ${ }^{71}$ In this report, $\alpha$-diarylphosphinoyl alcohols 33 were treated with alkynyl benziodoxoles $\mathbf{2}$ and BI-OAc $\mathbf{1 1}$ in the presence of photocatalyst $\mathbf{4}$ and phosphonoalkynes $\mathbf{3 4}$ were isolated in good to excellent yields (Scheme 13). The scope of substrates was studied extensively and substrates in which aryl groups attached with the phosphorus atom showed better reactivity compare to alkyl groups. The phosphorus- $\mathrm{C}\left(\mathrm{sp}^{3}\right)$ bond cleavage/alkynylation reactions proceeded via radical $\alpha$-addition of phosphorus radical to alkynyl benziodoxole $\mathbf{2}$. Actually, the phosphorus radical generates from alkoxyl radical which was formed by the reaction of $\alpha$-diarylphosphinoyl alcohol with BI-OAc 11. Interestingly, the protected $\alpha$ diarylphosphinoyl alcohols could not find the suitable substrates for these reactions. This a supporting evidence for the generation of alkoxyl radical.

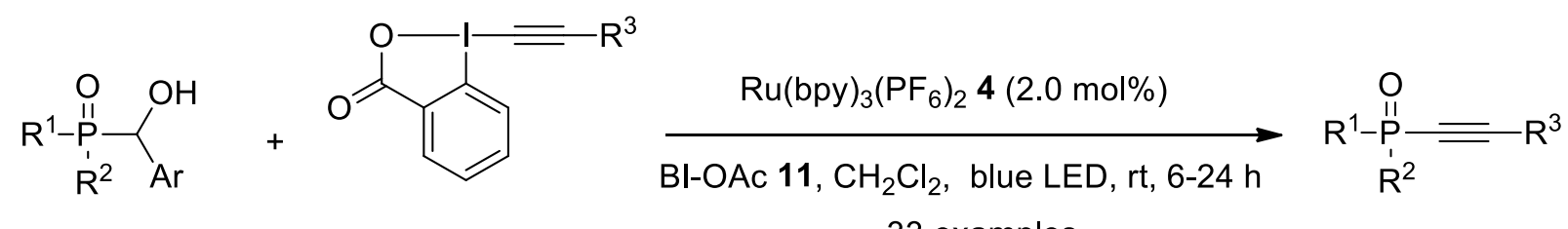

33

34: $63-90 \%$

$\mathrm{R}^{1} \& \mathrm{R}^{2}=$ cyclopentyl, $\mathrm{OMe}, \mathrm{NR}_{2}, \mathrm{Bn}, \mathrm{BnCH}_{2}, \mathrm{Ph}, 2$-thienyl, $3-\mathrm{MeC}_{6} \mathrm{H}_{4}, 4-\mathrm{MeC}_{6} \mathrm{H}_{4}, 3-\mathrm{OMeC}_{6} \mathrm{H}_{4}, 4-\mathrm{OMeC}_{6} \mathrm{H}_{4}, 4-\mathrm{FC}_{6} \mathrm{H}_{4}$, $3-\mathrm{ClC}_{6} \mathrm{H}_{4}, 4-\mathrm{FC}_{6} \mathrm{H}_{4}$ etc; $\mathrm{R}^{3}=$ TIPS, 3- $-\mathrm{OMeC}_{6} \mathrm{H}_{4}, 2-\mathrm{MeC}_{6} \mathrm{H}_{4}$, $3-\mathrm{MeC}_{6} \mathrm{H}_{4}, 4-\mathrm{MeC}_{6} \mathrm{H}_{4}, 4-\mathrm{ClC}_{6} \mathrm{H}_{4}, 4-\mathrm{FC}_{6} \mathrm{H}_{4}, 4-\mathrm{CHOC}_{6} \mathrm{H}_{4}$, 4$\mathrm{PhC}_{6} \mathrm{H}_{4}$ etc; $\mathrm{Ar}=\mathrm{Ph}, \mathrm{PMP}$.

Scheme 13. Photoredox-catalyzed phosphorus- $C\left(\mathrm{sp}^{3}\right)$ bond cleavage/alkynylation of $\alpha$-diarylphosphinoyl alcohols 33 to phosphonoalkynes 34 .

2.1.5. Alkynylation of cyclic oxime ethers. Recently, photoredox catalysis has been used successfully used to achieve alkynylation cascade of cyclic oxime ethers. ${ }^{72}$ In this report, fragmentation/alkynylation reaction of cyclic oxime ethers $\mathbf{3 5}$ was developed with ethynylbenziodoxolone (EBX) reagents $\mathbf{2}$ by using high reduction potential organic dye $\mathbf{3 6}$ as photocatalyst under mild reaction conditions. The reaction products $\mathbf{3 7}$ having 
nitrile and alkyne functionalities were isolated in good yields (Scheme 14). Organic dye 36 showed better photocatalytic potential in photoredox catalysis over the traditional iridium and ruthenium photo-catalysts due to its high reduction potential. During these transformations, alkyl nitrile radicals were generated via oxidative ring opening of cyclic alkyl ketone oxime ethers 35. Moreover, the redox properties of the dye were determined by cyclic voltammetry and computational studies.

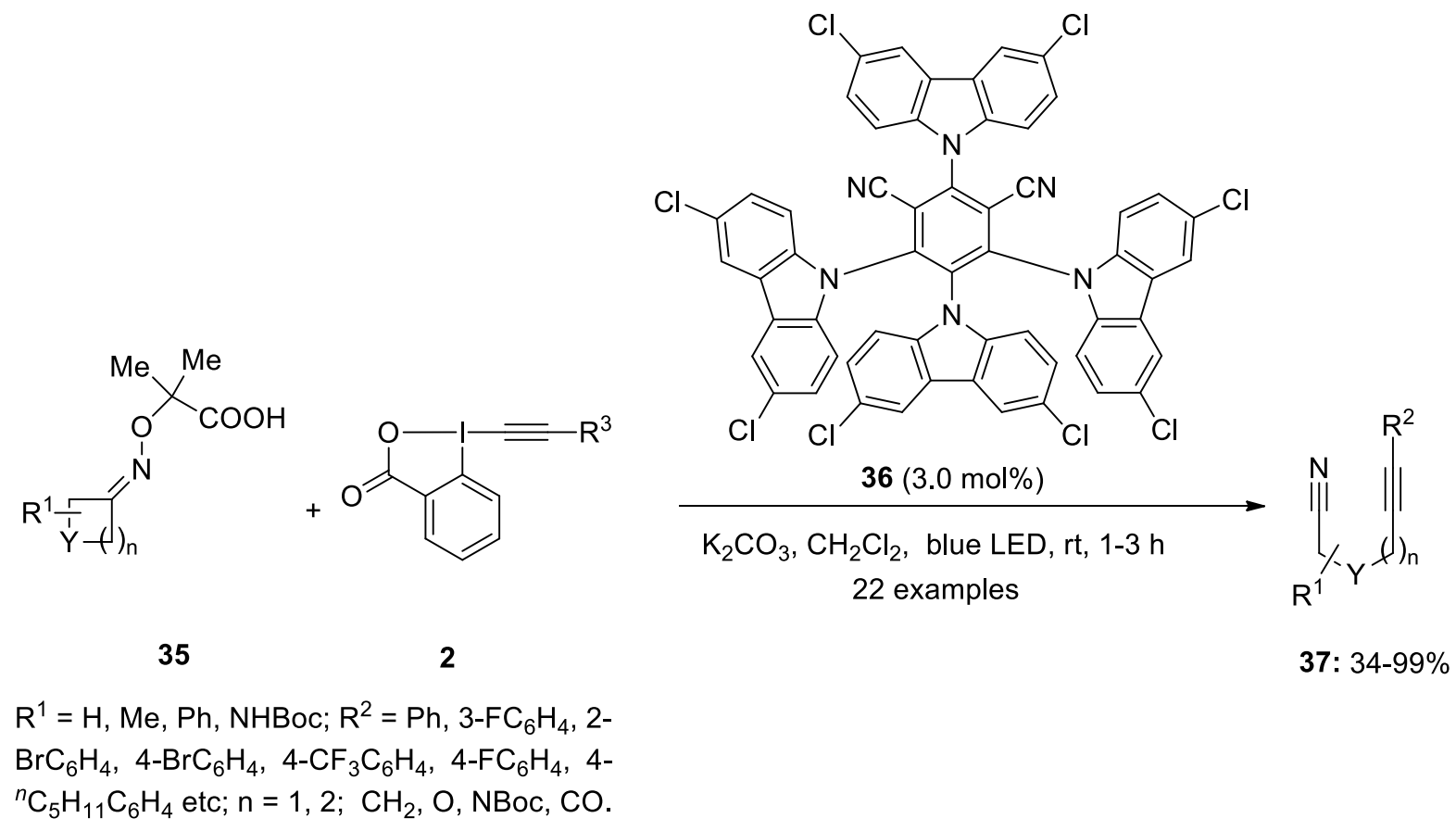

Scheme 14. Alkynylation cascade of cyclic oxime ethers 35 to reaction products $\mathbf{3 7}$ with EBX $\mathbf{2}$ by using organic dye $\mathbf{3 6}$ as photocatalyst.

2.1.6. Amidoalkynylation of unactivated alkenes. Jiang and Studer employed the photoredox catalysis for the 1,2-amidoalkynylation of unactivated alkenes 39 by using similar organic photo-catalyst $40 .{ }^{73}$ During these transformations, unactivated olefins 39 were treated with ethynylbenziodoxolone (EBX) reagents $\mathbf{2}$ and $\alpha$ amido-oxy acids $\mathbf{3 8}$ in the presence of organic photocatalyst $\mathbf{4 0}$ and reaction mixture was irradiated with blue light from blue LED. Reaction showed good functional group tolerance and 1,2-amidoalkynylation products $\mathbf{4 1}$ were obtained in good yields (Scheme 15). Amidoalkynylation was proceeded via amidyl radical formation which adds to the olefinic double bond to form adduct radicals. Eventually, adduct radicals trapped by EBX 2 to yield desired product 41. Moreover, photoredox catalysis showed a significant potential for the alkynylation of $\mathrm{C}\left(\mathrm{sp}^{3}\right)-\mathrm{H}$ bonds. ${ }^{74}$ 


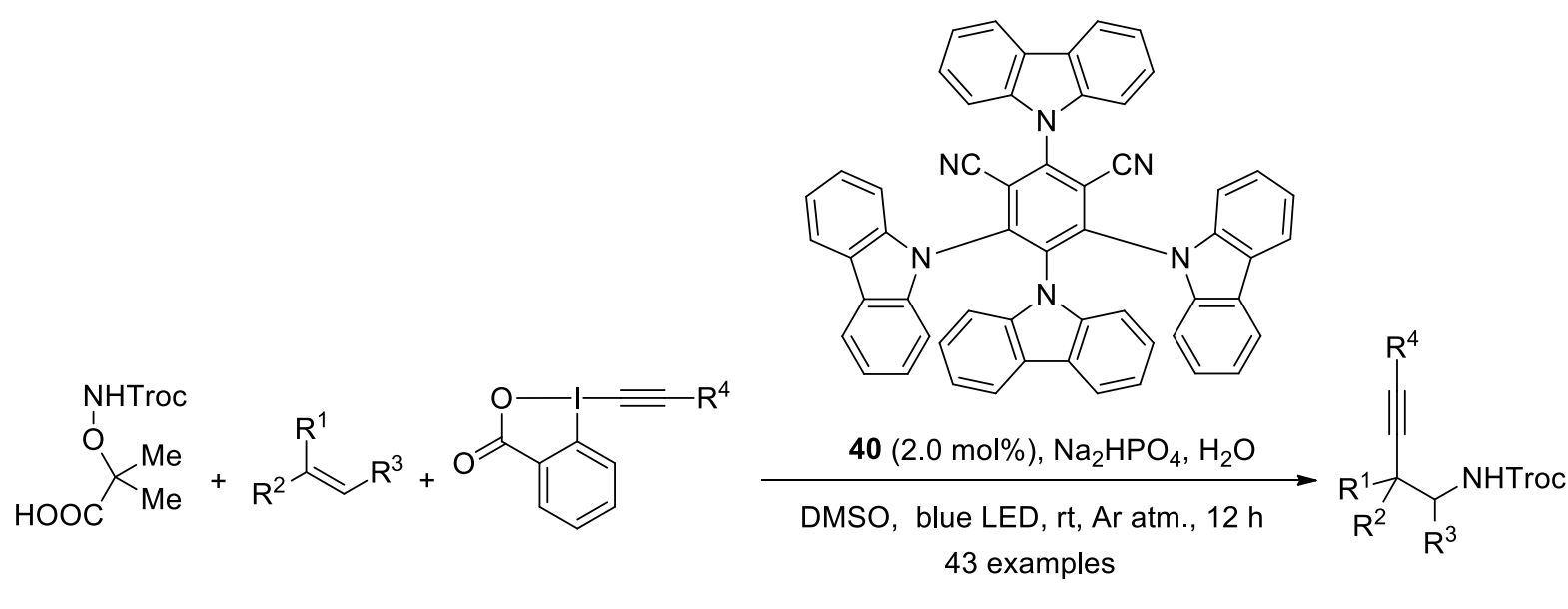

$\mathrm{R}^{1}=\mathrm{H}, \mathrm{Me}, \mathrm{Et}, \mathrm{nBu}, \mathrm{Bn}, \mathrm{CH}_{2} \mathrm{OH}, \mathrm{CH}_{2} \mathrm{OTs}$, OMe, OAc, OPh etc; $\mathrm{R}^{2}$ $=\mathrm{H}, \mathrm{Me}$, Et etc; $\mathrm{R}^{3}=\mathrm{H}, \mathrm{Me}, \mathrm{CH}_{2} \mathrm{OH}, \mathrm{CH}_{2} \mathrm{CH}_{2} \mathrm{Br}$ etc; $\mathrm{R}^{4}=\mathrm{Ph}, 4-$ $\mathrm{FC}_{6} \mathrm{H}_{4}, 4-\mathrm{BrC}_{6} \mathrm{H}_{4}, 4-\mathrm{MeC}_{6} \mathrm{H}_{4}, 4-\mathrm{CF}_{3} \mathrm{C}_{6} \mathrm{H}_{4}, 4-\mathrm{PhC}_{6} \mathrm{H}_{4}, 4-\mathrm{PhC}_{6} \mathrm{H}_{4}$.

Scheme 15. 1,2-Amidoalkynylation of unactivated alkenes 39 to products 41 with EBX 2 by using organic photoredox catalyst 40 .

\subsection{Alkenylation}

In 2015, Chen and co-workers reported the application of photoredox catalysis for alkenylation reactions by using hypervalent iodine reagents. ${ }^{75}$ In this report, potassium aryl/alkyl trifluoroborates 1 were treated with olefinic acids $\mathbf{4 2}$ and cyclic hypervalent iodine reagent $\mathbf{1 1}$ in the presence of photocatalyst $\mathbf{4}$ to afford the aryland acyl-substituted alkenes 43 in good yields (Scheme 16). During these transformations, a photoredox induced $\mathrm{C}\left(\mathrm{sp}^{3}\right)-\mathrm{C}\left(\mathrm{sp}^{2}\right)$ coupling reaction occurred via deboronation/decarboxylation sequence under aqueous reaction conditions. Actually, this was the beginning of radical decarboxylative alkenylation reaction using redox catalysis by involving hypervalent iodine reagents. Additionally, various sensitive functional groups were successfully tolerated during these transformations under mild reaction conditions.

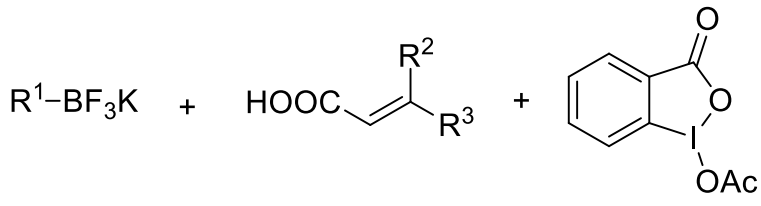

1
42

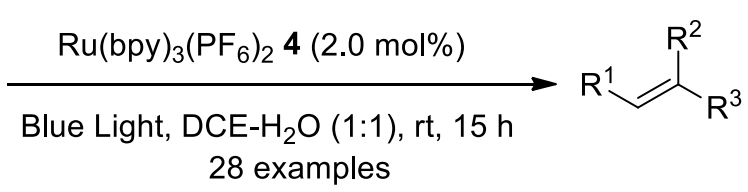

43: $58-87 \%$

$\mathrm{R}^{1}=1$-Indenyl, $\mathrm{Cy}, \mathrm{Bn}, \mathrm{CH}_{2} \mathrm{Bn}, 4-\mathrm{OMeC}_{4} \mathrm{H}_{4} \mathrm{CH}_{2}$ etc; $\mathrm{R}^{2}=\mathrm{H}$, $\mathrm{Me}, \mathrm{Ph}$ etc; $\mathrm{R}^{3}=2-\mathrm{MeC}_{4} \mathrm{H}_{4}, 3-\mathrm{MeC}_{4} \mathrm{H}_{4}, 4-\mathrm{MeC}_{4} \mathrm{H}_{4}, 4-$ $\mathrm{OMeC}_{4} \mathrm{H}_{4}, 4-\mathrm{FC}_{4} \mathrm{H}_{4}, 4-\mathrm{OHC}_{4} \mathrm{H}_{4}, 4-\mathrm{NH}_{2} \mathrm{C}_{4} \mathrm{H}_{4}, 4-\mathrm{NMe}_{2} \mathrm{C}_{4} \mathrm{H}_{4}$, 3thienyl, $\mathrm{CO}^{n} \mathrm{Bu}$, propargyl, allyl etc

Scheme 16. Photoredox induced $\mathrm{C}\left(\mathrm{sp}^{3}\right)-\mathrm{C}\left(\mathrm{sp}^{2}\right)$ coupling reaction of potassium trifluoroborates 1 with olefinic acids 42 via deboronation/decarboxylation sequence by involving BI-OAc 11.

The next report on the photoredox based alkenylation was came by same research group in $2016 .{ }^{69}$ In this approach, linear alcohol $\mathbf{4 4}$ was treated with olefinic carboxylic acids $\mathbf{4 2}$ by using ruthenium complex $\mathbf{4}$ as photoredox catalyst 4 and BI-OAC 11 as oxidant to undergo decarboxylative alkenylation in good yields 
(Scheme 17). During these alkenylations, BI-OAc 11 was used to achieve alkoxyl radicals by the oxidation of linear alcohol 44 which leads the cleavage of $C\left(s p^{3}\right)-C\left(s p^{3}\right)$ and alkenylation sequence. This was the first alkenylation approach following alkoxyl radical-induced $\mathrm{C}-\mathrm{C}$ bond cleavage using photoredox catalysis by involving cyclic hypervalent iodine reagents.

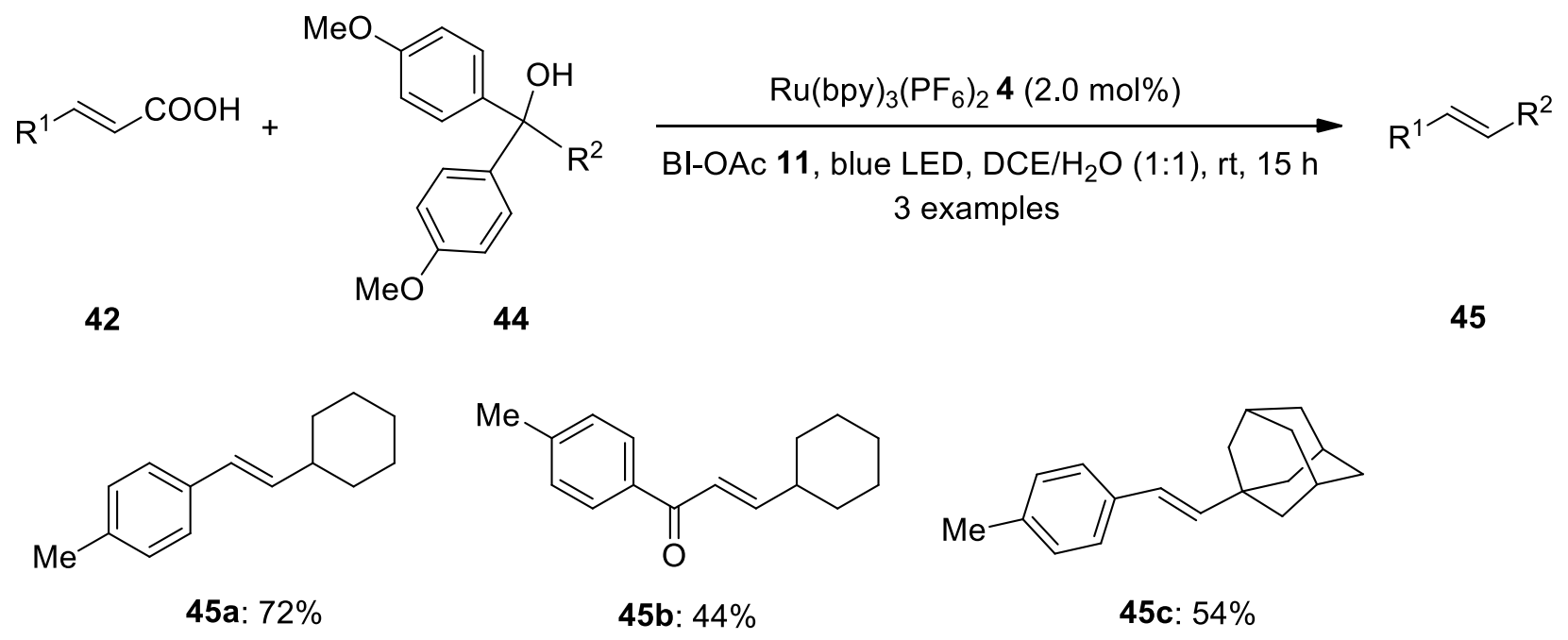

Scheme 17. Photoredox induced decarboxylative alkenylation of linear alcohol 44 with olefinic acids 42 via alkoxyl radical-induced $\mathrm{C}-\mathrm{C}$ bond cleavage/decarboxylation sequence by involving $\mathrm{BI}-\mathrm{OAc} \mathbf{1 1 .}$

\subsection{Cyanation reactions}

Cyanation is another reaction which has been achieved successfully by photoredox catalysis involving hypervalent iodine reagents. $\mathrm{Xu}$ and co-workers developed a direct method for deboronative cyanation of potassium alkyltrifluoroborate salts by using photoredox catalysis. ${ }^{76}$ In this reaction, potassium alkyltrifluoroborate salts $\mathbf{4 5}$ were treated with $p$-toluenesulfonyl cyanide $\mathbf{4 6}$ in the presence of photoredox catalyst 4 to achieve deboronative cyanation in good yields (Scheme 18). The cyanation reaction was proceeded by radical pathway and BI-OAC 11 was used to generate the alkyl radicals. TFA was used as an additive which was probably required to protonate the carboxylate ion formed during the reaction from an oxidant BI-OAc 11. Various primary alkyl trifluoroborates were successfully converted to corresponding alkyl cyanides in good yields.

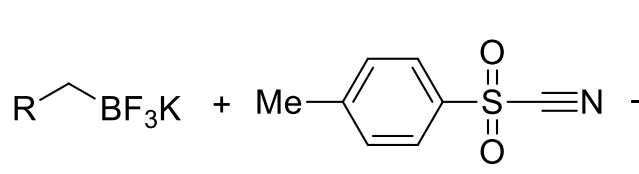

45

46
BIOAc 11 (3.0 equiv)

$\mathrm{Ru}(\mathrm{bpy})_{3}\left(\mathrm{PF}_{6}\right)_{2} 4$ (2.0 mol\%)

TFA (3.0 equiv), blue LED, $\mathrm{CH}_{2} \mathrm{Cl}_{2} / \mathrm{H}_{2} \mathrm{O}$ (1:1), rt, $24 \mathrm{~h}$

17 examples

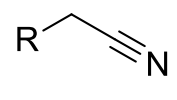

47: $45-82 \%$

$\mathrm{R}=\mathrm{Bn}, \quad 4-\mathrm{MeC}_{6} \mathrm{H}_{4} \mathrm{CH}_{2}, \quad 4-\mathrm{ClC}_{6} \mathrm{H}_{4} \mathrm{CH}_{2}$, Phth $\left(\mathrm{CH}_{2}\right)_{2} \mathrm{CH}_{2}, \quad \mathrm{PhOCH}_{2} \mathrm{CH}_{2}, \quad 4-\mathrm{CNC}_{6} \mathrm{H}_{4} \mathrm{OCH}_{2} \mathrm{CH}_{2}$, 4- $\mathrm{BrC}_{6} \mathrm{H}_{4} \mathrm{OCH}_{2} \mathrm{CH}_{2}, \mathrm{Me}\left(\mathrm{CH}_{2}\right)_{7} \mathrm{CH}_{2}$, $\mathrm{EtOOC}\left(\mathrm{CH}_{2}\right)_{3}$ etc.

Scheme 18. Photoredox-catalyzed deboronative cyanation of primary alkyltrifluoroborate salts 45 to corresponding alkyl cyanides using BI-OAc 11 as an oxidant. 
Furthermore, the same reaction conditions could not provide the effective results for the deboronative cyanation of secondary and tertiary alkyl trifluoroborate salts 48 . Interestingly, excess of $p$-toluenesulfonyl cyanide $\mathbf{4 6}$ was needed without using TFA to achieve the deboronative cyanation of both secondary and tertiary alkyl trifluoroborates in good yields (Scheme 19). Sensitive functional groups such as ether, cyano, ketone and ester showed good tolerance under given reaction conditions. Additionally, the deboronative cyanation of the alkyl trifluoroborates showed the complete dominance over aryl trifluoroborates when a competitive reaction was performed under same reaction conditions.
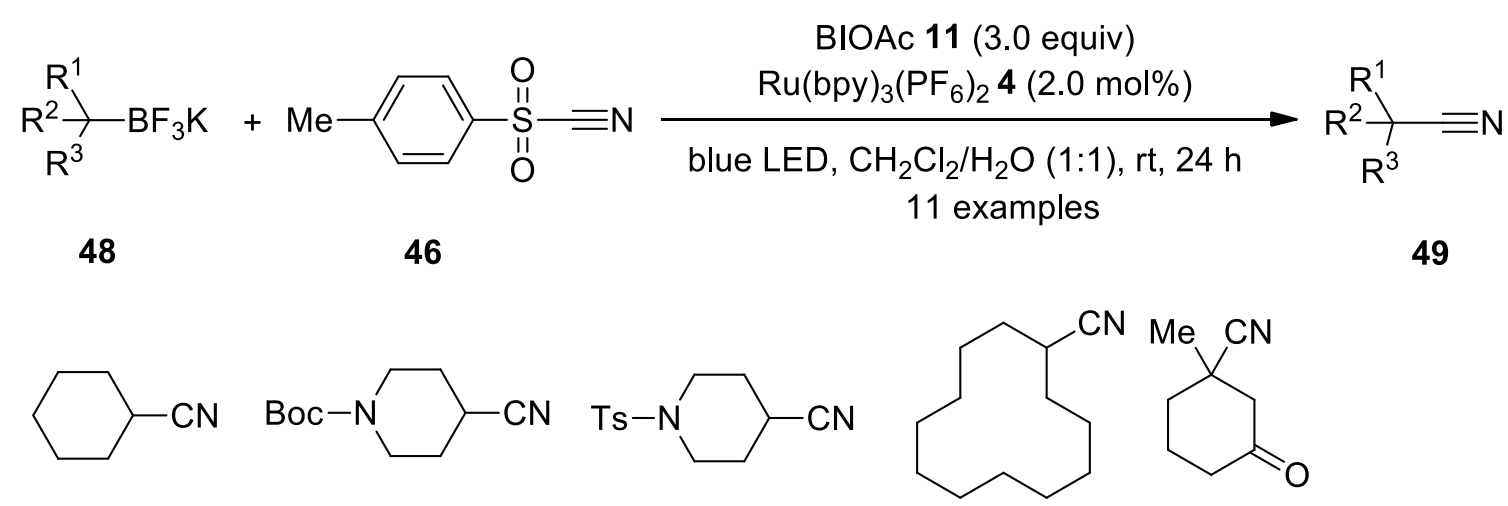

49a: $62 \%$

49b: $77 \%$

49c: $52 \%$

49d: $57 \%$

49e: $45 \%$<smiles>N#CC12CC3CC(CC(C3)C1)C2</smiles>

49f: $59 \%$<smiles>CC1(C#N)CCC(=O)C1</smiles>

49g: $41 \%$<smiles>[R]c1ccc(OCCC(C)C#N)cc1</smiles>

49h: $\mathrm{R}=\mathrm{OMe} ; 37 \%$

49i: $\mathrm{R}=\mathrm{CN} ; 87 \%$

49j: $R=$ COPh; $43 \%$<smiles>CC(C)Cc1ccc(C(C)C(=O)OCC(C)C#N)cc1</smiles>

49k: $47 \%$

Scheme 19. Photoredox-catalyzed deboronative cyanation of secondary and tertiary alkyltrifluoroborate salts 48 to corresponding alkyl cyanides 49 using excess of $p$-toluenesulfonyl cyanide 46.

In 2018, Waser and his co-workers developed the cyanation of aliphatic carboxylic acids by using photoredox catalysis. ${ }^{77}$ Decarboxylative cyanation of various synthetic and natural amino acids $\mathbf{5 0}$ was achieved in good yields by using cyanobenziodoxolones (CBX) $\mathbf{5 1}$ as an oxidant and source of cyanide species in the presence of iridium-based photoredox catalyst $\mathbf{2 1}$ and base. Various sensitive groups in amino acids were successfully tolerated under given reaction conditions and corresponding cyanides were obtained in good yields (Scheme 20). Moreover, the reaction showed good potential for the cyanation of dipeptides and some drug precursors. As like photoredox alkynylation reactions, the reaction followed the radical pathway. Recently, cyanobenziodoxolones (CBX) $\mathbf{5 1}$ has been used for the cyanation of amines by using electrophilic nitrogen radical under photoredox reaction conditions. ${ }^{74}$ 


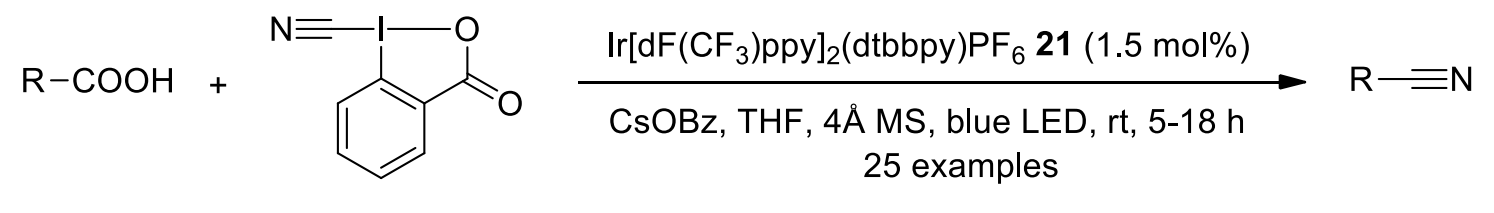

50

53: $43-92 \%$

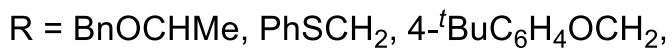

cyclic and acyclic amines etc.

Scheme 20. Photoredox-catalyzed decarboxylative cyanation of amino acids $\mathbf{5 0}$ to corresponding alkyl cyanides 49 using cyanobenziodoxolones (CBX) 51 as source of cyanide species.

\subsection{C-H Alkylation reactions}

Photoredox catalysis has been shown a significant potential for the $\mathrm{C}-\mathrm{H}$ alkylation reactions. Photoredoxcatalyzed Minisci $\mathrm{C}-\mathrm{H}$ alkylation of $\mathrm{N}$-heteroarenes $\mathbf{5 3}$ was developed with alkyl boronic acids $\mathbf{5 4}$ in the presence of visible light in HFIP by using BI-OAc $\mathbf{1 1}$ as an oxidant and ruthenium complex $\mathbf{5 5}$ as photoredox catalyst (Scheme 21). Various primary and secondary alkyl groups were successfully incorporated in different $N$-heterocycles under mild reaction conditions and alkylated $\mathbf{N}$-heterocycles $\mathbf{5 6}$ were isolated in high yields except the alkylation of quinolines. Moreover, this approach was efficiently used for the alkylation of complex natural products and drug molecules. ${ }^{78}$ Probably, the reaction was working by forming an intramolecularly stabilized ortho-iodobenzoyloxy radical intermediate.

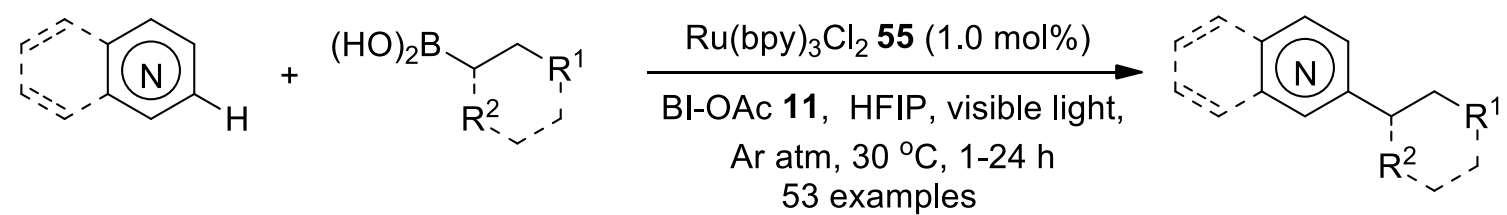

53

56: $11-96 \%$

$\mathrm{R}^{1}=\mathrm{H}, \mathrm{Me}$, Et, Ar etc; $\mathrm{R}^{2}=\mathrm{H}, \mathrm{Me}$, Et etc;

$\mathrm{R}^{1} \& \mathrm{R}^{2}=$ cyclic systems.

Scheme 21. Photoredox-catalyzed Minisci $\mathrm{C}-\mathrm{H}$ alkylation of $\mathrm{N}$-heteroarenes $\mathbf{5 3}$ with alkyl boronic acids $\mathbf{5 4}$ to alkylated $\mathrm{N}$-heterocycles $\mathbf{5 1 .}$

Furthermore, the photoredox catalysis was used for the alkylation of pyridine $\mathrm{N}$-oxides $\mathbf{5 7}$ at $\mathrm{C} 2$ position. ${ }^{79}$ Once again the ruthenium complex 4 was used as photoredox catalyst while potassium alkyl trifluoroborates salts 1 were sued as source of alkyl species. The alkylated pyridine $\mathbf{N}$-oxides $\mathbf{5 8}$ were isolated in good yields (Scheme 22). Cyclic hypervalent iodine reagent (BI-OAC) 11 was used to generate the ortho-iodobenzoyloxy radical which found as the reaction intermediate for these transformations. Notably, the reaction showed significant substrates tolerance under given reaction conditions. 


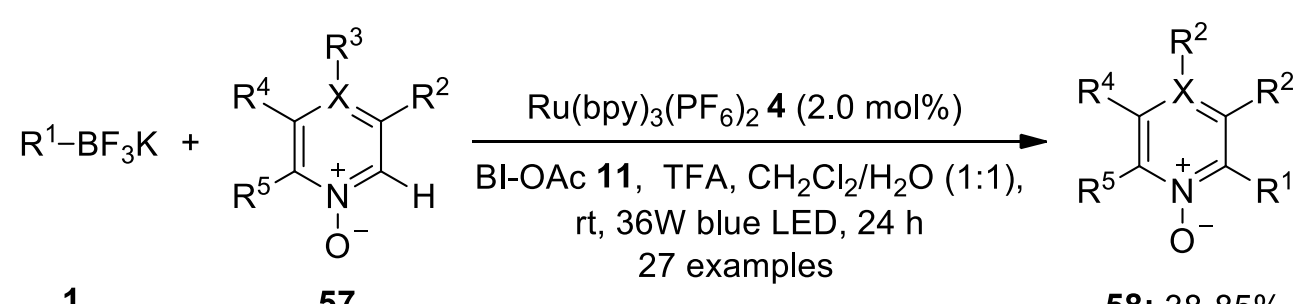

$\mathrm{R}^{1}=\mathrm{Me}, \mathrm{Cy}, \mathrm{Cy}$-pentyl, $\mathrm{CH}_{2} \mathrm{CH}_{2} \mathrm{CH}_{2} \mathrm{OAr} ; \mathrm{R}^{2}$

$=\mathrm{H}, \mathrm{F} ; \mathrm{R}^{3}=\mathrm{H}, \mathrm{Me}, \mathrm{NHBoc}, \mathrm{CF}_{3}, \mathrm{OBn} ; \mathrm{R}^{4}=$

$\mathrm{H}, \mathrm{Me} ; \mathrm{R}^{5}=\mathrm{H}, \mathrm{Me}, \mathrm{Cl}, \mathrm{CH}_{2} \mathrm{CH}_{2} \mathrm{OH} ; \mathrm{X}=\mathrm{C}, \mathrm{N}$

58: $38-85 \%$

Scheme 22. Photo-catalyzed alkylation of pyridine $\mathbf{N}$-oxides $\mathbf{5 7}$ at $\mathrm{C} 2$ position with potassium alkyl trifluoroborates salts 1 .

\subsection{Arylation reactions}

In past few years, the attention of few hypervalent iodine chemists has been shifted towards the development of arylation reactions by using photoredox catalysis. In 2016, Denton and co-workers reported the arylation of trisubstituted phosphines $\mathbf{5 9}$ with diaryliodonium triflates $\mathbf{6 0}$ in the presence of visible light by using ruthenium based photoredox catalyst 61 (Scheme 23). ${ }^{80}$ The reactions were completed in short reaction time and aryl phoshonium salts $\mathbf{6 2}$ were isolated in good yields. This reaction involves the coupling of phosphines with aryl radical and provides quaternary aryl phoshonium salts which are quite unique in organic synthesis.

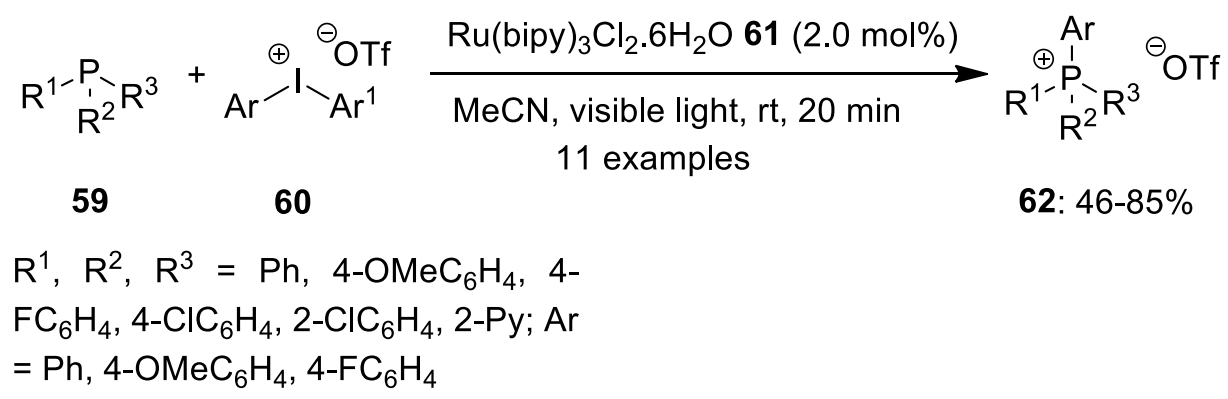

Scheme 23. Arylation of phosphines $\mathbf{5 9}$ with diaryliodonium triflates $\mathbf{6 0}$ by ruthenium based photoredox catalysis.

Furthermore, different photoredox catalysts were designed and used in photoredox-catalyzed arylation of amines. ${ }^{81}$ Photoredox-catalyzed three component reaction afforded functionalized $\mathrm{N}$-aminosulfonamides 65 in good yields by the reaction of diaryliodonium salts 60 , hydrazines 63 and $\mathrm{SO}_{2}$ in the presence of perylenediimide (PDI) 64 photoredox catalyst (Scheme 24). Actually, sulfur dioxide was generated in situ either by the acid-mediated decomposition of potassium bisulfite or added as the sulfur dioxide surrogate DABCO-(SO $\left.\mathrm{S}_{2}\right)_{2}$. The scope of substrates was studied in detail and different aryl groups in salts and hydrazines were successfully tolerated under mild reaction conditions. 


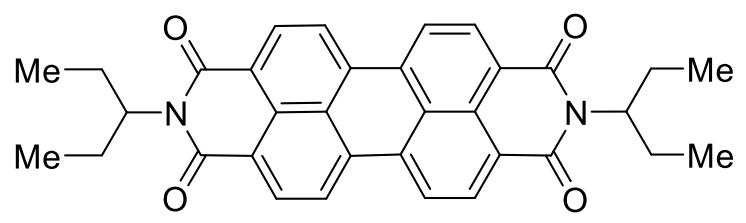

64: $2.0 \mathrm{~mol} \%$

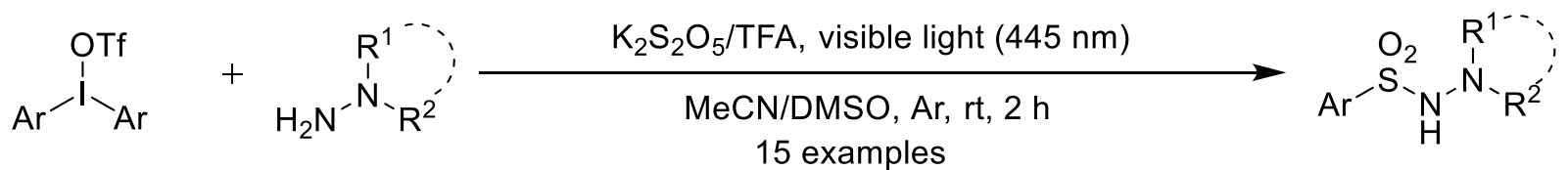

60

63

65: $23-74 \%$

$\mathrm{Ar}=\mathrm{Ph}, 4-\mathrm{MeC}_{6} \mathrm{H}_{4}, 4-\mathrm{ClC}_{6} \mathrm{H}_{4}, 4-\mathrm{BrC}_{6} \mathrm{H}_{4}$, $4-\mathrm{OMeC}_{6} \mathrm{H}_{4}, \quad 2,5-\mathrm{Me}_{2} \mathrm{C}_{6} \mathrm{H}_{3}, \quad 2, \quad 4, \quad 6-$ $\mathrm{Me}_{3} \mathrm{C}_{6} \mathrm{H}_{2} ; \mathrm{R}^{1}, \mathrm{R}^{2}=\mathrm{Me}, \mathrm{Ph}, \mathrm{Bn}, \mathrm{H}$;

Scheme 24. Photoredox-catalyzed synthesis of functionalized $N$-aminosulfonamides 65 by three component reaction of diaryliodonium salts 60 , hydrazines 63 and $\mathrm{SO}_{2}$ by using photoredox catalyst 64 .

The catalytic cycle for the photoredox-catalyzed arylation of hydrazines 63 is depicted in scheme 25 . The catalytic cycle was initiated by the reaction of hydrazine 63 with sulfur dioxide to form a stable hydrazinesulfur dioxide adduct 68. On the other hand, the photoredox catalytic species PDI 64 absorb the light and gets excited to form photoexcited PDI* 66. The excited photoexcited PDI* 66 further undergo reductive quenching on reaction with adduct $\mathbf{6 8}$ to form radical cation $\mathbf{7 0}$ along with the formation of reduced catalytic species 69 . The radical cation $\mathbf{7 0}$ gave radical adduct $\mathbf{7 1}$ on deprotonation. Furthermore, the diaryliodonium salt $\mathbf{6 0}$ gets reduced into intermediate $\mathbf{7 2}$ via electron-transfer process from reduced catalytic species 69 and generates PDI 64 in its ground state. The reduced species $\mathbf{7 2}$ further fragments into aryl radical $\mathbf{7 4}$ along with the formation of aryl iodide $\mathbf{7 3}$. Finally, the free-radical addition (FRA) of aryl radical $\mathbf{7 4}$ with the radical adducts $\mathbf{7 1}$ yields the final product $\mathbf{6 5}$. The other possibility for the proceeding of this reaction is the formation of chargetransfer complex 75 which playing as a key role to absorb visible light directly. 


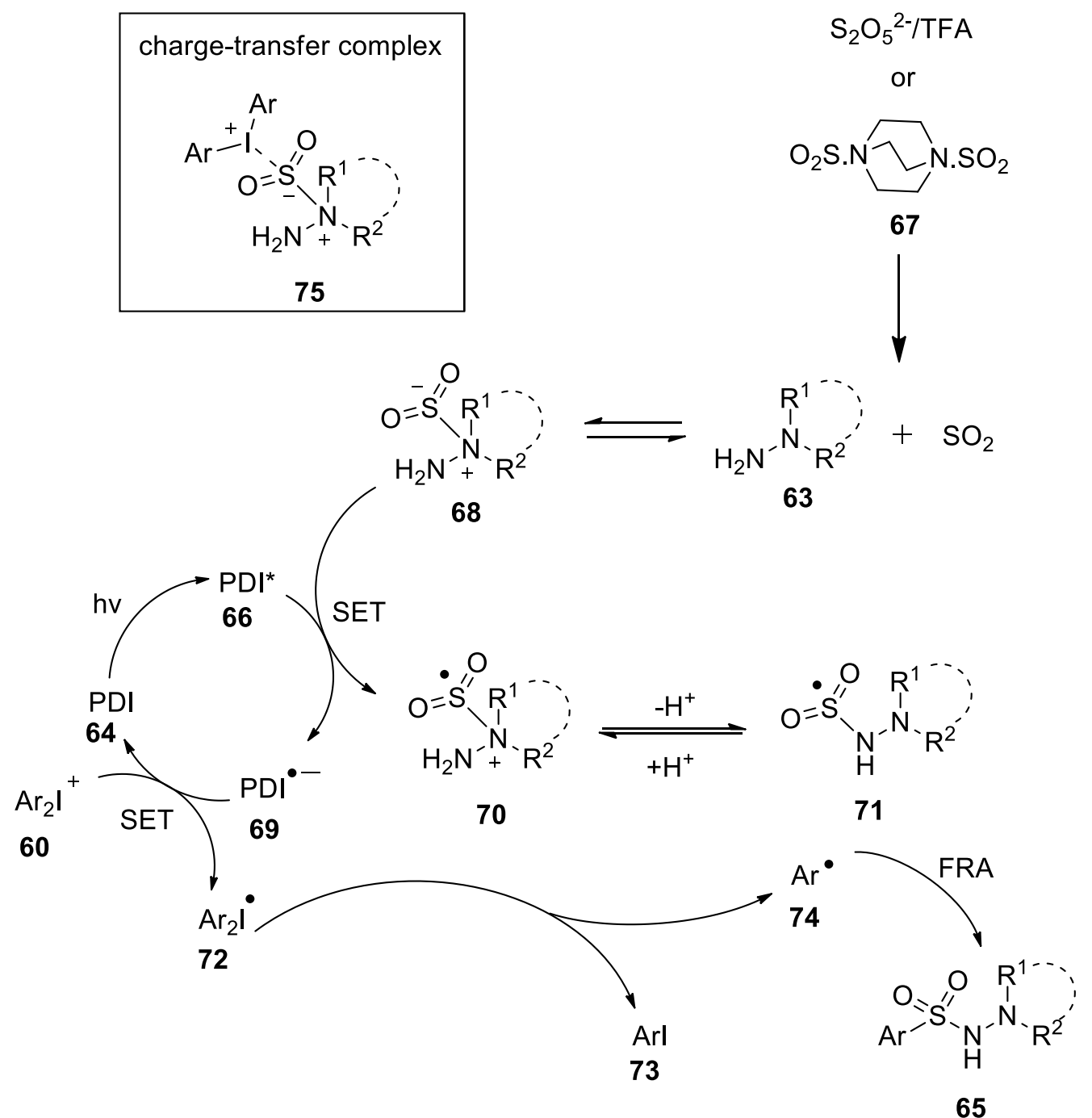

Scheme 25. Catalytic cycle for the photoredox-catalyzed synthesis of functionalized $N$-aminosulfonamides 65 via three component reaction of diaryliodonium salts 60 , hydrazines 63 and $\mathrm{SO}_{2} \mathrm{BY}$ using photo-catalyst 64 .

Recently, photoredox catalysis has been used for the arylation of quinoline $N$-oxides 76 at $\mathrm{C} 2$ position by using diaryliodonium tetrafluoroborates $\mathbf{7 7}$ as arylation reagent in the presence of eosin $\mathrm{Y} \mathbf{7 8}$ photoredox catalyst. ${ }^{81}$ Most of the reaction were required three days to complete and variety of $\mathrm{N}$-heterobiaryls $\mathbf{7 9}$ were isolated in good to excellent yields (Scheme 26). Interestingly, arylation reaction was not found quite effective in case of ruthenium and iridium based photoredox catalysts while organic dye eosin $Y \mathbf{7 8}$ showed great potential as photoredox catalyst during these transformations. Moreover, this approach was applicable for the arylation of pyridine $\mathrm{N}$-oxides under similar reaction and conditions. 


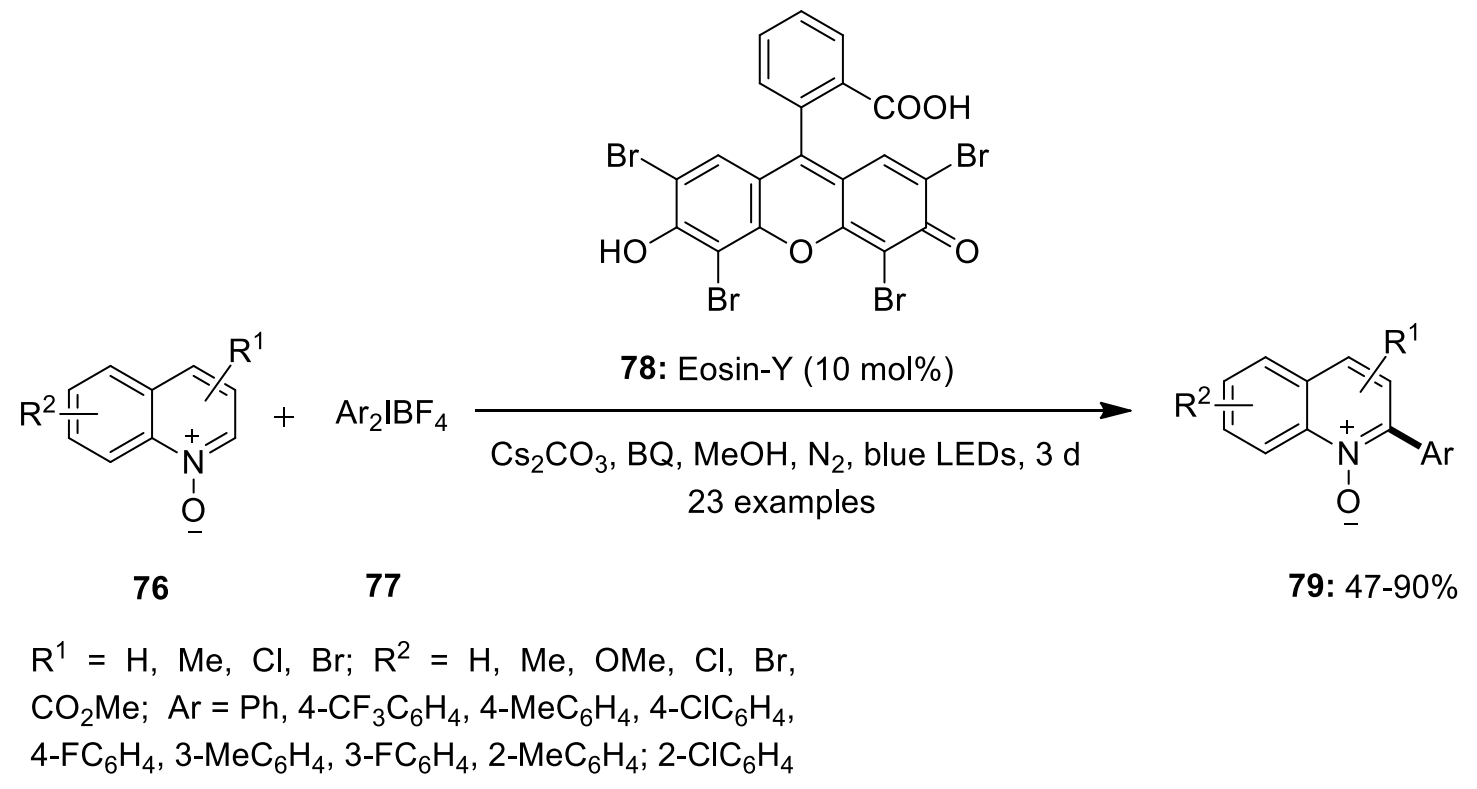

Scheme 26. Photoredox-catalyzed arylation of quinoline $\mathrm{N}$-oxides 76 at $\mathrm{C} 2$ position by using diaryliodonium tetrafluoroborates $\mathbf{7 7}$ as arylation reagent and eosin $Y \mathbf{7 8}$ as photoredox catalyst.

\subsection{C-H Diazomethylation of arenes}

Photoredox catalysis involving hypervalent iodine reagents has been used to achieve $\mathrm{C}$-H diazomethylation of arenes. In 2018, Suero and co-workers reported the synthesis of novel hypervalent iodine reagent $\mathbf{8 0}$ and used successfully for $\mathrm{C}-\mathrm{H}$ diazomethylation of arenes $\mathbf{8 1}$ under mild reaction conditions. ${ }^{83}$ During these diazomethylation reactions, the newly synthesized hypervalent iodine compound $\mathbf{8 0}$ was reacted with different functionalized arenes $\mathbf{8 1}$ in the presence of base by using $1.0 \mathrm{~mol} \%$ of ruthenium based photocatalytic species $\mathbf{4}$. The reaction mixture was irradiated with while LED and diazomethylated arenes $\mathbf{8 2}$ were isolated in good to excellent yields (Scheme 27). In case of disubstituted arenes, the generated radicals reacts preferentially at electron rich site and corresponding functionally arenes were obtained in excellent yields. Notably, the reaction occurred at the ortho-position in case of mono-substituted alkenes. Additionally, unsubstituted arenes were efficiently diazomethylated under same reaction conditions. Different cyclic and pseudocyclic hypervalent reagents cored with diazo group were used in this reaction but diazo was transferred more efficiently in case of pseudocyclic hypervalent reagents.

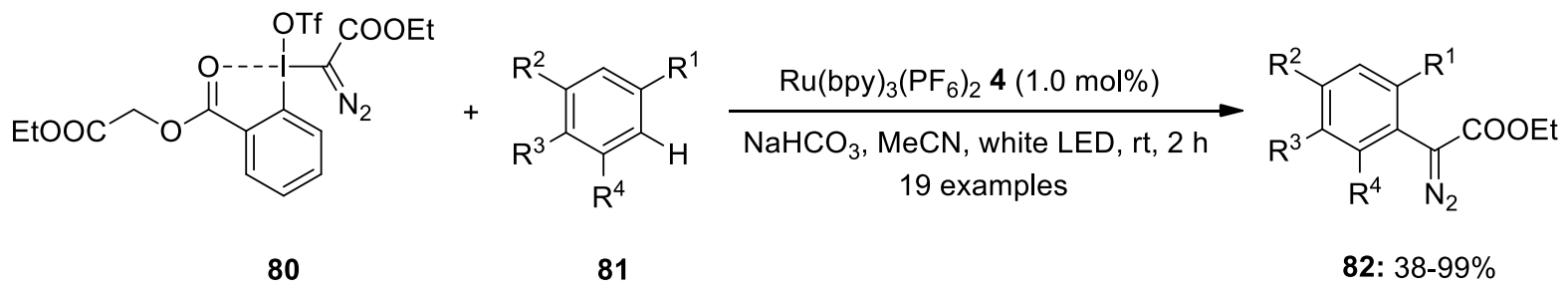

$\mathrm{R}^{1}=\mathrm{H}, \mathrm{Me}, \mathrm{OMe}, \mathrm{CH}_{2}{ }^{i} \mathrm{Pr},{ }^{i} \mathrm{Pr}, \mathrm{Br}, \mathrm{I}, \mathrm{NHBoc}$, COOMe; $\mathrm{R}^{2}=\mathrm{H}$, Me; R3 $=\mathrm{H}, \mathrm{Me},{ }^{t} \mathrm{Bu}$, TMS, $\mathrm{CF}_{3}, \mathrm{~F}, \mathrm{COOMe}$ etc; $\mathrm{R} 4=\mathrm{H}, \mathrm{Me}$.

Scheme 27. C-H Diazomethylation of substituted and unsubstituted arenes $\mathbf{8 1}$ using iodine(III) reagent $\mathbf{8 0}$ as diazo group transfer reagent using photoredox catalysis. 
Moreover, this reaction was used efficiently for diazomethylation of various complex naturally occurring compounds and drug molecules. Interestingly, the expected product was not obtained when isobutylbenzene $\mathbf{8 3}$ was used as a substrate under same reaction condition and racemic indane derivative $\mathbf{8 4}$ was isolated in $32 \%$ yields (Scheme 28). Probably, the cyclization reaction was proceeded via double site-selective $\mathrm{C}-\mathrm{H}$ functionalization reaction. Moreover, the valuable chiral building blocks were synthesized under same reaction conditions.

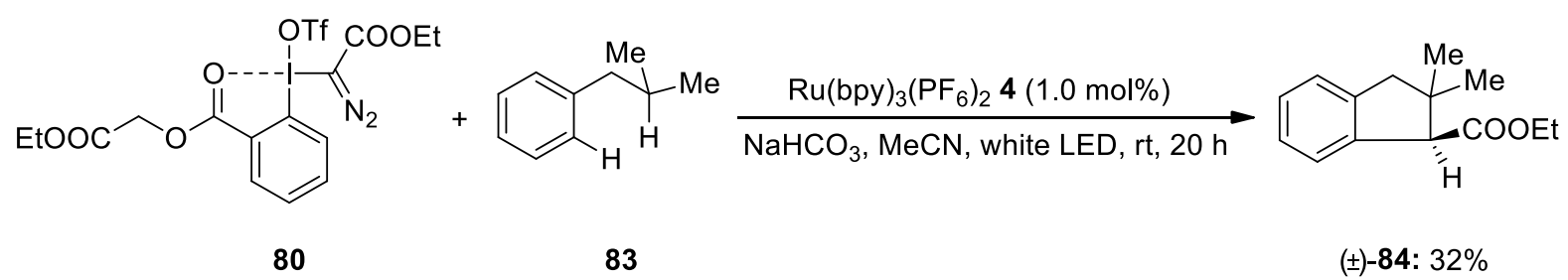

Scheme 28. Photoredox-catalyzed cyclization of isobutylbenze 83 to indane derivative 84 with iodine(III) reagent $\mathbf{8 0}$ in the presence of ruthenium-based photoredox catalyst 4.

\subsection{Azidation reactions}

In 2015, Waser and co-workers developed ring expansions by photoredox catalysis using copper based new photoredox catalyst 83. ${ }^{84}$ Cyclic hypervalent iodine reagent $\mathbf{8 3}$ (azidobenziodazolone) were synthesized and used for the photoredox-catalyzed azidation reactions of olefins $\mathbf{8 2}$ cored with spirocyclic ring in the presence of copper-based photoredox catalyst 84. The reaction mixture was irradiated with green light and new azides 85 were obtained in high yields (Scheme 29). The azidation reactions were irradiated with green LED and ring expansion was observed along with azidation.

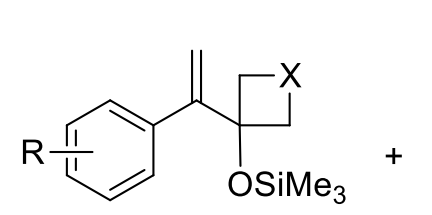

85<smiles>N#[As]I1C(=O)c2ccccc21</smiles>

(1.2 equiv.)

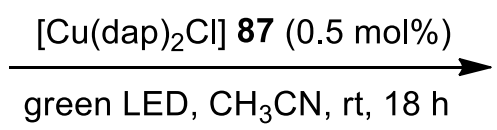

19 examples

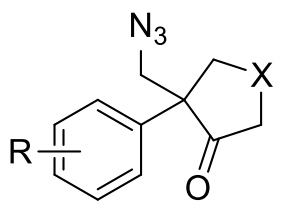

88: $58-96 \%$ $\mathrm{R}^{1}=\mathrm{H}, \mathrm{Me}, t \mathrm{Bu}, \mathrm{Ph}, \mathrm{OMe}$, $\mathrm{F}, \mathrm{Cl} ; \mathrm{X}=\mathrm{CH}_{2}, \mathrm{O}$, NBoc

Scheme 29. Photoredox-catalyzed azidation of olefins $\mathbf{8 5}$ to azides $\mathbf{8 8}$ with ABZ (azidobenziodazolone) 86 in the presence of copper-based photoredox catalyst $\mathbf{8 7}$.

Similar reagents were further explored in other azidation reactions such as azidation of olefinic acids and different arenes. Azidation/lactonization was observed when the same reagent $\mathbf{8 6}$ was treated with olefinic acid $\mathbf{8 9}$ under same reaction conditions. The reaction proceeded well and azide-cored lactone $\mathbf{9 0}$ was isolated in $81 \%$ yield (Scheme 30$).{ }^{84}$ 


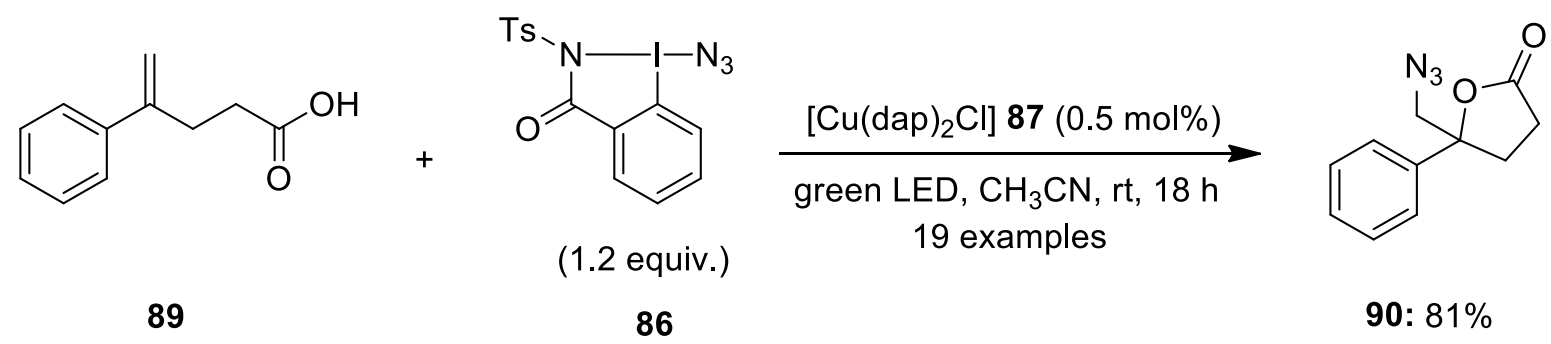

Scheme 30. Photoredox-catalyzed azidation/lactonization of olefinic acid 89 to azide-cored lactone $\mathbf{9 0}$ with ABZ (azidobenziodazolone) 83 in the presence of photoredox catalyst $\mathbf{8 7 .}$

\subsection{Trifluoromethylation reactions}

Trifluoromethylation reactions are the key functionalizations in organic synthesis and achieved by using different electrophilic trifluoromethylating agents. ${ }^{85,86}$ In the past two decades, Togni reagents have been successfully used as source of trifluoromethyl electrophile to achieve different trifluoromethylation reactions. ${ }^{87}$ Few photoredox reactions have been successfully developed to achieve different trifluoromethylation reactions using Togni reagents. ${ }^{88,89}$ In 2012, Togni's reagents was used to generate trifluoromethyl $\left(\mathrm{CF}_{3}\right)$ radical in the presence of photoredox catalyst. ${ }^{90}$ furthermore, Zhu and coworkers developed the trifluoromethylation of $\mathrm{N}$-acrylamides using photoredox catalysis by involving Togni's reagent. ${ }^{91}$ In 2013, Akita and co-workers developed the trifluoromethylation of vinyltrifluoroborates $\mathbf{9 1}$ in the presence of ruthenium complex $\mathbf{4}$ as photoredox catalyst by using Togni's reagent $\mathbf{9 2}$ as a $\mathrm{CF}_{3}$ radical. All the reactions were irradiated with blue LED and trifluoromethylated olefins $\mathbf{9 3}$ were obtained in good yields with high selectivity (Scheme 31)..$^{92}$

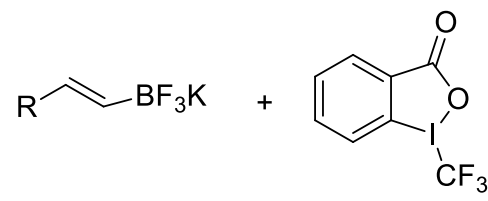

91
92

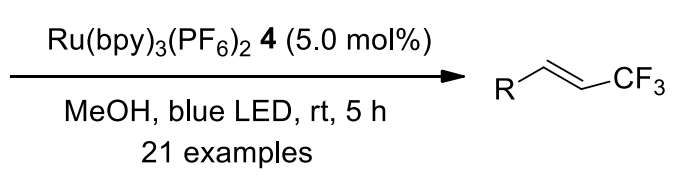

93: $68-88 \%$

$\mathrm{R}=\mathrm{Ph}, \mathrm{Bn}, 3-\mathrm{Py}, 2-\mathrm{MeC}_{6} \mathrm{H}_{4}, 4-\mathrm{MeC}_{6} \mathrm{H}_{4}$, 4-

$\mathrm{OMeC}_{6} \mathrm{H}_{4}, 4-\mathrm{ClC}_{6} \mathrm{H}_{4}, 4-\mathrm{CF}_{3} \mathrm{C}_{6} \mathrm{H}_{4}, 4-\mathrm{CNC}_{6} \mathrm{H}_{4}$ etc

Scheme 31. Photoredox-catalyzed trifluoromethylation of vinyltrifluoroborates 91 in the presence of ruthenium complex 4 as photoredox catalyst by serving Togni's reagent 92 as a source of $\mathrm{CF}_{3}$ radical.

Gouverneur and co-workers reported the trifluoromethylation of allylsilanes $\mathbf{9 4}$ under similar photoredox catalytic system by using Togni's reagent $\mathbf{9 2}$ as source of trifluoromethyl group. The trifluoromethylation reactions were working smoothly and reaction products 95 were obtained in good yields except few reactions (Scheme 32). ${ }^{93}$ 


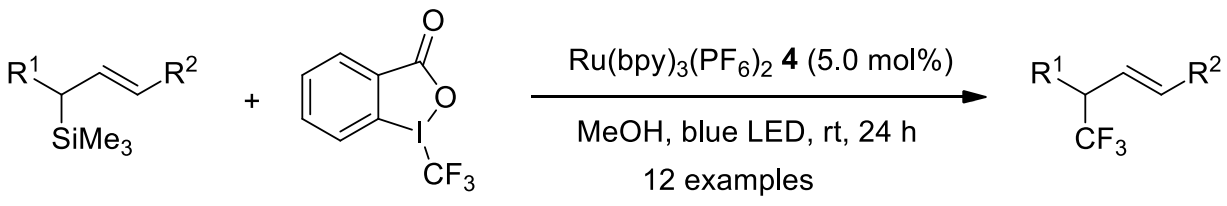

94

92

95: $22-83 \%$

$\mathrm{R}^{1}=\mathrm{Me}, \mathrm{BnCH}_{2} ; \mathrm{R}^{2}=\mathrm{CH}_{2} \mathrm{COOEt}, \mathrm{CH}(\mathrm{Me}) \mathrm{COOEt}$,

$\mathrm{CH}(\mathrm{Bn}) \mathrm{COOEt}, \mathrm{CH}(\mathrm{OMe}) \mathrm{COOEt}, \mathrm{CH}\left({ }^{i} \mathrm{Pr}\right) \mathrm{COOEt}$ etc

Scheme 32. Photoredox-catalyzed trifluoromethylation of allylsilanes 94 in the presence of ruthenium complex 4 as photoredox catalyst by serving Togni's reagent 92 as a source of $\mathrm{CF}_{3}$ radical.

Furthermore, the Togni's reagent 92 was used to achieve the decarboxylative trifluoromethylation of $\alpha, \beta$ unsaturated carboxylic acids 96 using $\operatorname{Ir}(\mathrm{ppy})_{3} \mathbf{9 7}$ as photoredox catalyst under alkaline reaction conditions. Wide range of substrates were successfully tolerated and trifluoromethylated alkenes $\mathbf{9 8}$ were obtained in good yields with excellent stereoselectivity (Scheme 33). ${ }^{94}$

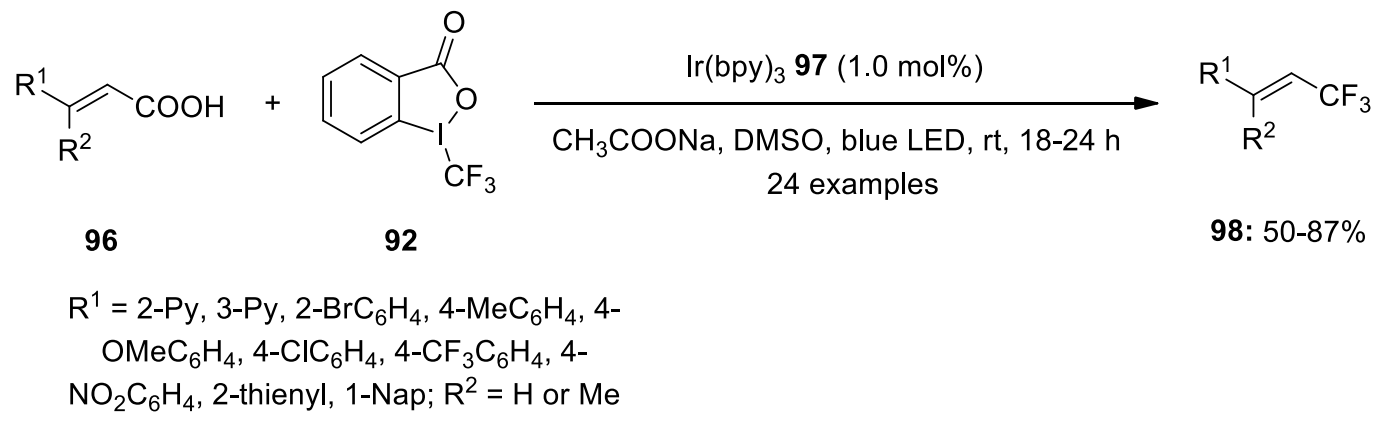

Scheme 33. Photoredox-catalyzed trifluoromethylation of $\alpha, \beta$-unsaturated acids 96 in the presence of iridium complex 97 as photoredox catalyst using same $\mathrm{CF}_{3}$ radical 92.

The same iridium based photoredox catalyst $\operatorname{Ir}(\mathrm{ppy})_{3} \mathbf{9 7}$ was used for the trifluoromethylation of unprotected anilines 99 using Togni's reagent 92 as trifluoromethyl radical source and trifluoromethylated anilines $\mathbf{1 0 0}$ were obtained in moderate to good yields (Scheme 34). ${ }^{95}$ Various electron withdrawing and donating groups were successfully tolerated and yields of the products were not much influenced by the electronic effect. Interestingly, trifluoromethylated products were obtained as single regioisomers in case of $p$ substituted anilines while mixture of regioisomers was observed in case of $o$ - or $m$-substituted anilines. Additionally, Togni reagent $\mathbf{9 2}$ was used to develop photoredox catalyzed oxy-, amino-, and carbotrifluoromethylation reactions with good success. ${ }^{96}$ 
<smiles>[R]c1ccc([CH+])c(N)c1[R]</smiles>

97

92

100: $38-81 \%$

$\mathrm{R}^{1}=\mathrm{H}$, COOMe, $\mathrm{CONH}_{2}, \mathrm{Ph} ; \mathrm{R}^{2}=\mathrm{H}$,

$\mathrm{OMe}, \mathrm{Br}, \mathrm{NHSO}_{2} \mathrm{Me}, 4-\mathrm{ClC}_{6} \mathrm{H}_{4} ; \mathrm{R}^{3}=\mathrm{H}, \mathrm{Cl}$,

$\mathrm{Br}, \mathrm{I}, \mathrm{COOMe}, \mathrm{COMe}$, CONHMe, CN,

OMe, 2-Py, Ph etc

Scheme 34. Photoredox-catalyzed trifluoromethylation of unprotected anilines $\mathbf{9 9}$ in the presence of iridium complex 97 as photoredox catalyst using same $\mathrm{CF}_{3}$ radical 92 .

\subsection{Conversion of arylboronic acids to phenols}

In 2015, Yadav and co-workers reported the conversion of arylboronic acids 101 to corresponding phenols 103 by using organic photoredox catalysis under mild reaction conditions. ${ }^{97}$ During these transformations, the organic dye eosin $Y 78$ was used as photoredox catalyst and $\mathrm{Phl}(\mathrm{OAc})_{2} 102$ was used to generate the radical species. All the reactions were performed in the presence of visible light and functionalized phenols 103 were isolated in excellent yields (Scheme 35). Organic photoredox catalytic species could be excited in the presence of light and reacts with $\mathrm{Phl}(\mathrm{OAc})_{2} 102$ to form the methyl radical which plays a vital role for conversion of arylboronic acids to phenols.<smiles>O=C(O)c1ccccc1-c1c2cc(Br)c(=O)c(Br)c-2oc2c(Br)c(O)c(Br)cc12</smiles><smiles>[R]c1ccc(Br)c([R])c1</smiles>

101

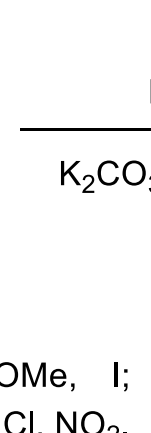

78: Eosin-Y (1.0 mol\%)

$\mathrm{Phl}(\mathrm{OAc})_{2} 102(50 \mathrm{~mol} \%)$

$\mathrm{CO}_{3}, \mathrm{MeCN}, \mathrm{N}_{2}$, visible light, $\mathrm{rt}, 6 \mathrm{~h}$ 8 examples

103: $87-96 \%$

$$
\begin{aligned}
& \mathrm{R}^{1}=\mathrm{H}, \mathrm{OMe}, \quad \mathrm{I} ; \\
& \mathrm{R}^{2}=\mathrm{H}, \mathrm{Br}, \mathrm{I}, \mathrm{Cl}, \mathrm{NO}_{2} .
\end{aligned}
$$

Scheme 35. Photoredox-catalyzed conversions of arylboronic acids 101 to phenols 103 by using photoredox catalysis. 


\section{Photochemical Reactions without Photoredox Catalysis}

There are few photochemical reactions developed by involving hypervalent iodine reagents without using any photoredox catalyst. In this section, non-photoredox photochemical reactions achieved in past few years using hypervalent iodine reagents have been would be covered.

\subsection{Aminocyclization reactions}

In 2015, iodine-catalyzed aminocyclizations of substituted butyl amines 104 was developed by using $\mathrm{Phl}(m \mathrm{CBA})_{2} 105$ as an oxidant and molecular iodine as catalyst in the presence of visible light. ${ }^{98}$ The cyclization reactions were working smoothly and substituted pyrrolidines 106 were obtained in good to excellent yields (Scheme 36). This approach was found quite useful to construct the fused pyrrolidine scaffolds in good yields. Various sensitive functional groups were successfully tolerated under given reaction conditions.

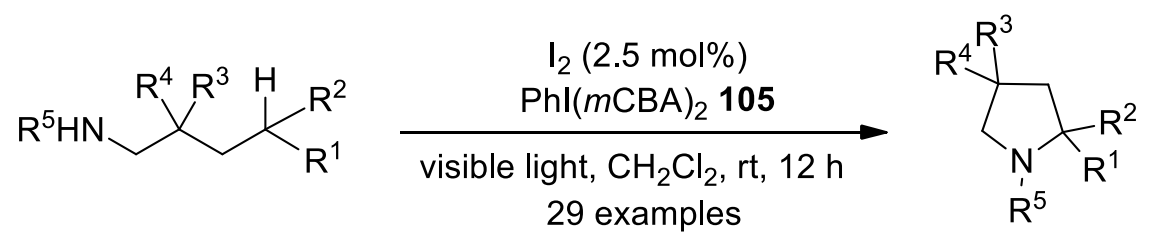

104

106: $65-98 \%$

$$
\begin{aligned}
& \mathrm{R}^{1}=\mathrm{H}, \mathrm{Me}, \mathrm{Ph} ; \mathrm{R}^{2}=\mathrm{H}, \mathrm{Me}, \mathrm{OMe}, \mathrm{Bn}, \mathrm{Ph}, 4- \\
& \mathrm{FC}_{6} \mathrm{H}_{4}, \quad 4-\mathrm{ClC}_{6} \mathrm{H}_{4}, \quad 4-\mathrm{BrC}_{6} \mathrm{H}_{4}, \quad 4-\mathrm{MeC}_{6} \mathrm{H}_{4}, \quad 4- \\
& \mathrm{OMeC}_{6} \mathrm{H}_{4} ; \mathrm{R}^{3}=\mathrm{H}, \mathrm{Me}, \mathrm{Ph} \mathrm{R}^{4}=\mathrm{H}, \mathrm{Me}, \mathrm{Ph} ; \mathrm{R}^{5}= \\
& \mathrm{SO}_{2} \mathrm{Me}, \mathrm{SO}_{2}-4-\mathrm{MeC}_{6} \mathrm{H}_{4}, \mathrm{SO}_{2}-4-\mathrm{NO}_{2} \mathrm{C}_{6} \mathrm{H}_{4}
\end{aligned}
$$

Scheme 36. Visible light-mediated iodine-catalyzed aminocyclizations of aliphatic amines 104 to pyrrolidines 106 by using $\mathrm{Phl}(m \mathrm{CBA})_{2} 105$ as an oxidant.

The catalytic cycle for the visible light-mediated iodine-catalyzed aminocyclizations of aliphatic amines 104 to pyrrolidines $\mathbf{1 0 6}$ is discussed in scheme 37. The catalytic cycle was initiated with formation of in situ generated catalytic species I $(m C B A) \mathbf{1 0 8}$ which further reacts with the amine 104 to form crucial intermediate 109. The $\mathrm{N}-\mathrm{I}$ bond of the intermediate 109 cleaved homolytically in the presence of visible light and form radical 110 . The nitrogen-centered radical undergo 1,5-hydrogen atom abstraction to generate carboncentered radical 111. Radical intermediate $\mathbf{1 1 1}$ reacts with iodine radical and forms iodinated intermediate 112. Furthermore, the iodine atom of intermediate 112 was oxidized by $\mathrm{Phl}(m \mathrm{CBA})_{2} 105$ to iodine(III)intermediate 113. Finally, intermediate 113 cyclizes to final product 106 by involving $\mathrm{N}-\mathrm{H}$ and carbon attached to iodine(III) species and generates I(mCBA) 108 to enter into the next catalytic cycle. Notably, the free acid 107 stabilizes the active catalytic species 108 and regenerated upon dissociation. 


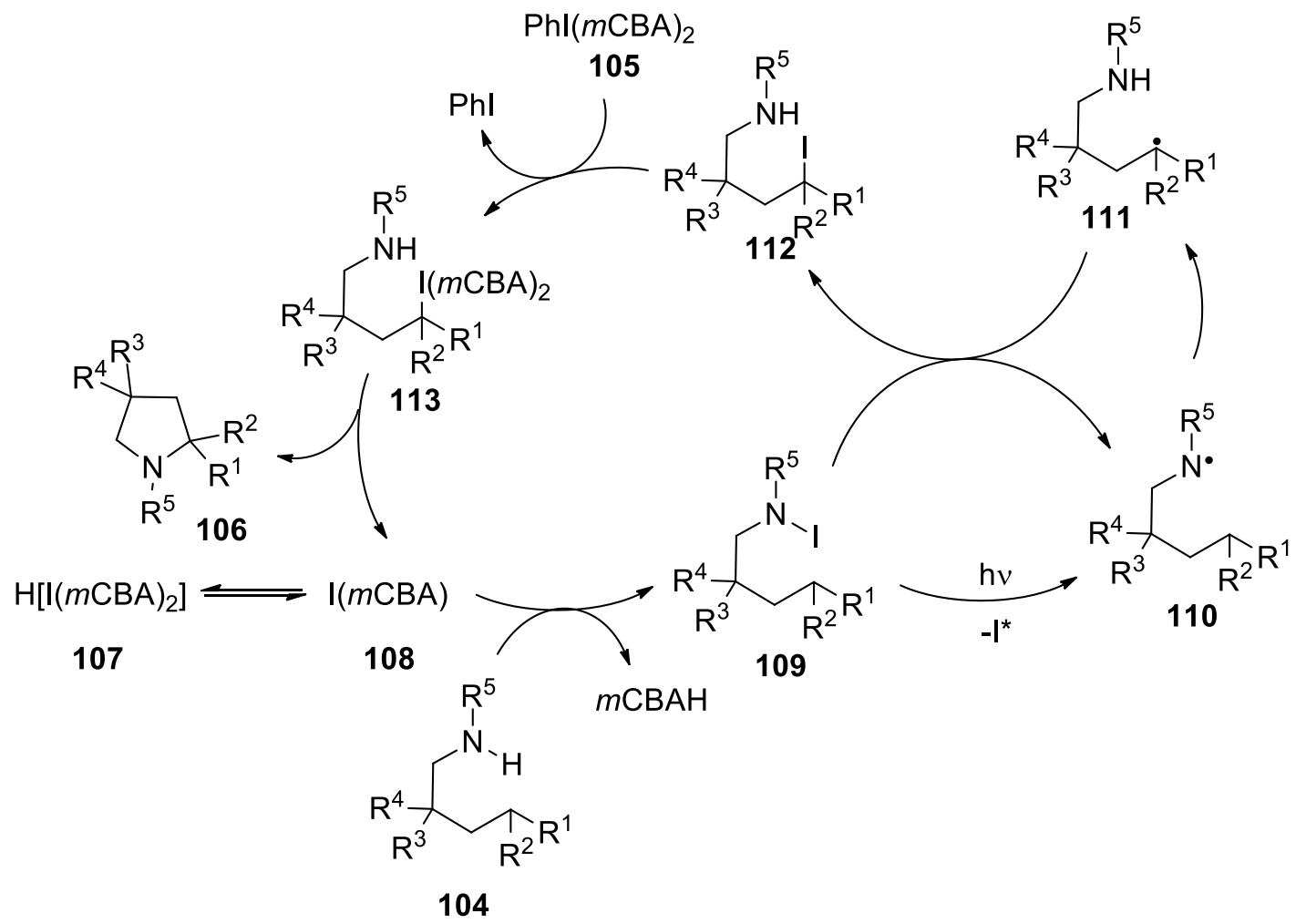

Scheme 37. Catalytic cycle for visible light-mediated iodine-catalyzed aminocyclizations of aliphatic amines 104 to pyrrolidines 106 by using Phl $(m C B A)_{2} 105$ as an oxidant.

Nagib and co-workers reported triiodide-mediated aminocyclization of unactivated amines 114 to functionalized pyrrolidines $\mathbf{1 1 5}$ in the presence of visible light without using any photo-catalyst. ${ }^{99}$ Triiodide $^{2}$ species was generated in situ by the oxidation of iodide species using Phl(OAc) 2102 as an oxidant and functionalized pyrrolidines $\mathbf{1 1 5}$ were obtained in good to excellent yields (Scheme 38). Different functional groups showed good tolerance during these aminocyclizations.

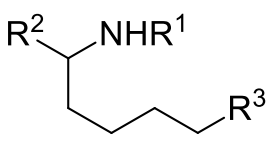

114

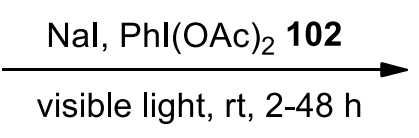

22 examples

$\mathrm{R}^{1}=\mathrm{Ts}, \mathrm{Ns}, \mathrm{Ms}, \mathrm{SES} ; \mathrm{R}^{2}=\mathrm{H}, \mathrm{Me}, \mathrm{CH}_{2} \mathrm{OAc}$,

$\mathrm{CF}_{3}$, COOMe, $\mathrm{CH}_{2} \mathrm{COOMe}, \mathrm{CH}_{2} \mathrm{COPh}, \mathrm{Ph}$,

$4-\mathrm{FC}_{6} \mathrm{H}_{4}, 4-\mathrm{OMeC}_{6} \mathrm{H}_{4} ; \mathrm{R}^{3}=\mathrm{H}, \mathrm{Me},{ }^{n} \mathrm{Pr}, \mathrm{Ph}$

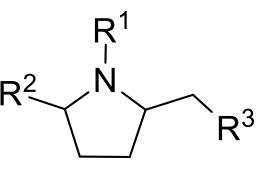

115: $58-93 \%$

Scheme 38. Triiodide-mediated aminocyclization of unactivated amines 114 to pyrrolidines 115.

\subsection{Decarboxylative acylarylation}

In 2015, Wang and co-workers reported an iodine(III)-catalyzed decarboxylative acylarylation of acrylamides 116 with ketoacids $\mathbf{1 0}$ in the presence of visible-light without using photoredox catalyst to afford functionalized 2-oxindoles 117 in good yields (Scheme 39). ${ }^{100}$ BI-OAc 11 was used to generate the radical 
species by cleavage of oxygen-iodine bond in the presence of blue LED (450-455 nm). Various electron donating and withdrawing groups in benzene ring of substrates $\mathbf{1 1 6}$ were used but the course of reaction was quite similar and produced 2-oxindoles in almost similar yields. Notably, the yields were slightly enhanced when electron donating substituents were installed in the aryl ring of ketoacids $\mathbf{1 0 .}$

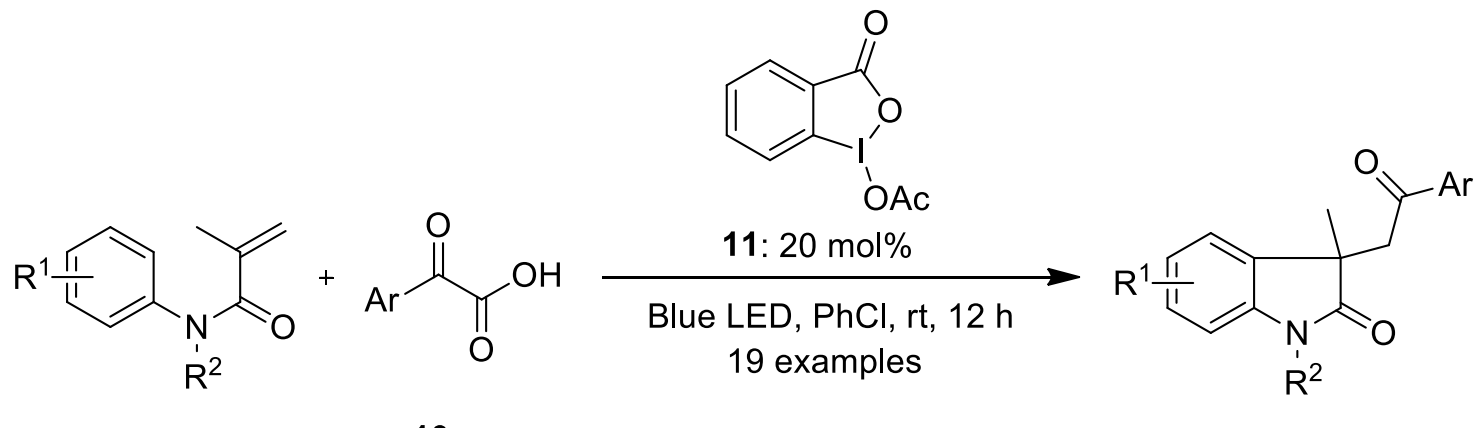

116

10

117: $58-84 \%$

$\mathrm{R}^{1}=\mathrm{H}, \mathrm{Me}, \mathrm{OMe}, \mathrm{OEt}, \mathrm{F}, \mathrm{Cl}, \mathrm{Br}, \mathrm{I}, \mathrm{Ph}, \mathrm{CO}_{2} \mathrm{Et} ; \mathrm{R}^{2}=\mathrm{Me}$,

$\mathrm{Et}, p-\mathrm{Cl}-\mathrm{Bn}, p-\mathrm{Me}-\mathrm{Bn}, m-\mathrm{Me}-\mathrm{Bn} ; \mathrm{Ar}=\mathrm{Ph}, 4-\mathrm{MeC}_{6} \mathrm{H}_{4}$, 3-

$\mathrm{MeC}_{6} \mathrm{H}_{4}, 2-\mathrm{MeC}_{6} \mathrm{H}_{4}, 4-\mathrm{EtC}_{6} \mathrm{H}_{4}, 4-\mathrm{OMeC}_{6} \mathrm{H}_{4}, 4-\mathrm{FC}_{6} \mathrm{H}_{4}, 4-$

$\mathrm{ClC}_{6} \mathrm{H}_{4}, 4-\mathrm{BrC}_{6} \mathrm{H}_{4}$, 1-Nap, 2-Nap.

Scheme 39. lodine(III)-catalyzed decarboxylative acylarylation of acrylamides 116 with ketoacids 10 to 2oxindoles 117 driven by visible light.

A plausible mechanism for iodine(III)-catalyzed decarboxylative acylarylation of acrylamides 114 to 2oxindoles 117 driven by visible light is depicted in scheme 40. The catalytic cycle was initiated with transesterification of $\mathrm{BI}-\mathrm{OAC} \mathbf{1 1}$ with ketoacid $\mathbf{1 0}$ to intermediate 118. Intermediate $\mathbf{1 1 8}$ undergo homolytic cleavage in the presence of visible light and forms benzoyl radical $\mathbf{1 1 9}$ and iodanyl radical $\mathbf{1 2 0}$ followed by the release of $\mathrm{CO}_{2}$. Furthermore, the formation of another intermediate $\mathbf{1 2 1}$ occurred by the free radical addition of radical 119 to olefinic double bond of substrate 116. Finally, the intermediate 121 yields the cyclized product 117 on hydrogen atom abstraction and form another intermediate 122. Intermediate 122 further releases hydrogen gas and afford the intermediate $\mathbf{1 1 8}$ to enter in the next catalytic cycle. 


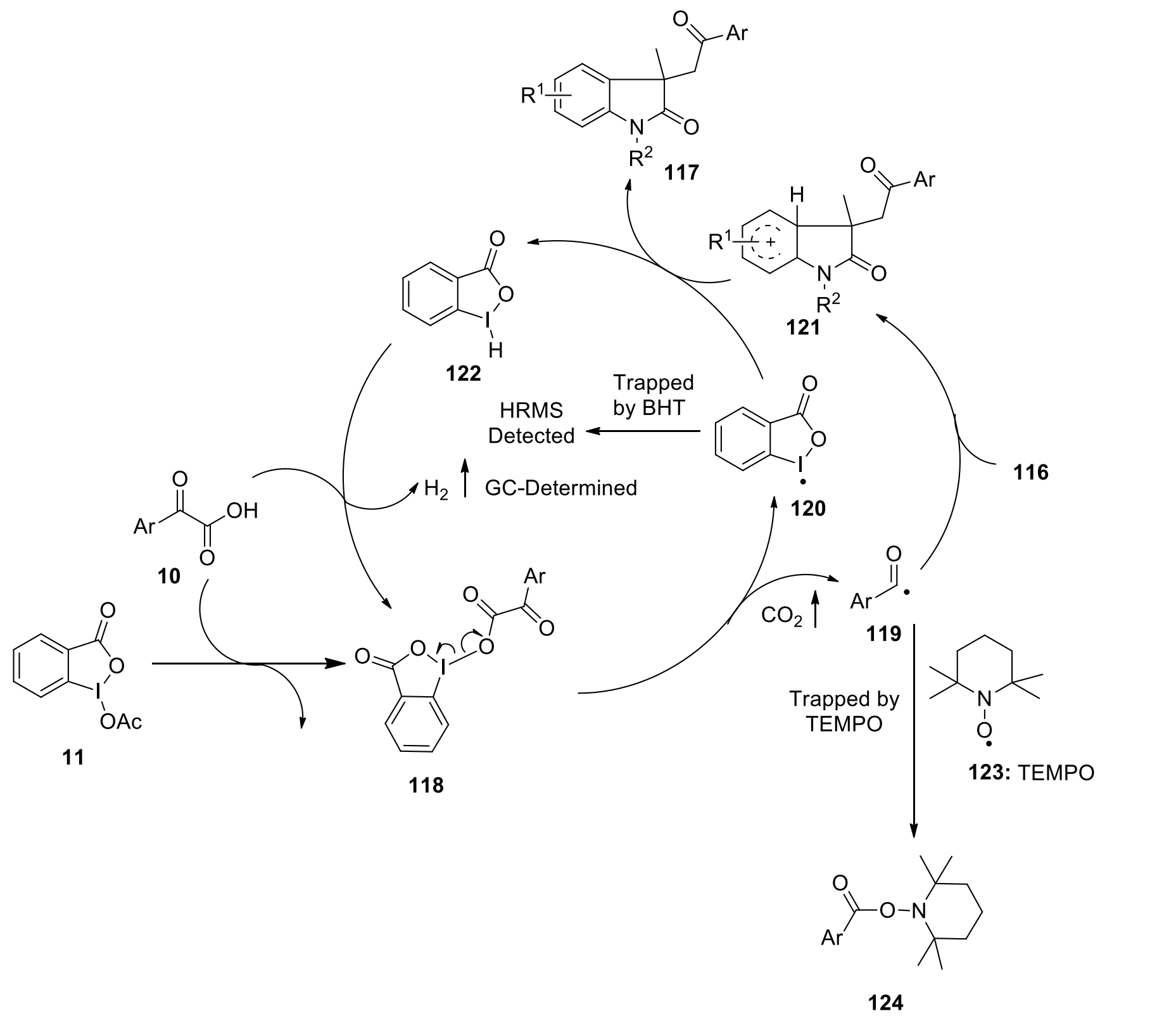

Scheme 40. Catalytic cycle for iodine(III)-catalyzed decarboxylative acylarylation of acrylamides 116 to 2 oxindoles 117 driven by visible light.

\subsection{Cyclopropanation reaction}

Recently, a photochemical cyclopropanation of olefins was developed by the reaction with iodonium ylides without using any photoredox catalyst. ${ }^{101}$ During these transformations, the reaction mixture of olefins 117 and $\beta$-dicarbonyl-derived iodonium ylides 124-126 was irradiated with blue light obtained from blue LED and doubly activated cyclopropanes $\mathbf{1 2 8}$ were obtained in good to excellent yields (Scheme 41). The cyclopropanation reaction proceeded well with cyclic and acyclic iodonium ylides and showed versatility with different electronically diverse olefins. 


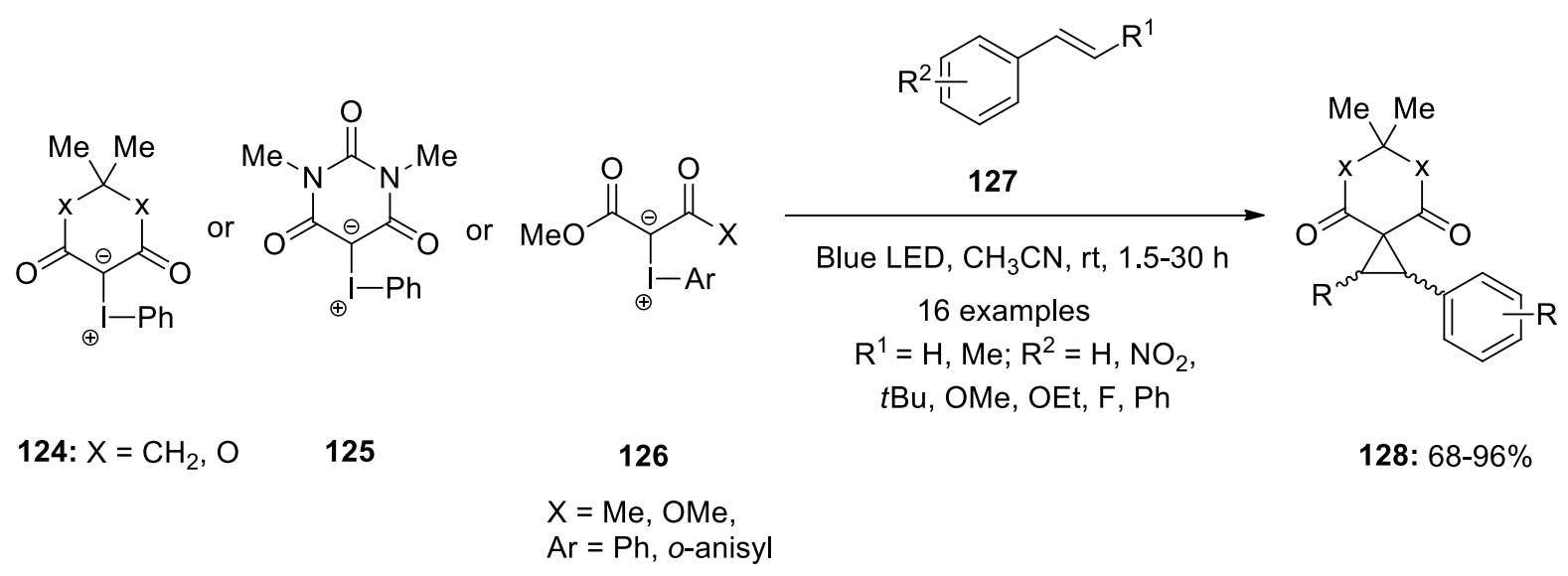

Scheme 37. Cyclopropanation of olefins 127 with iodonium ylides 124-127 in the presence of blue light without using any photoredox catalyst.

\section{Conclusions}

In this review article, we have summarized various photochemical reactions by involving hypervalent iodine reagents. The combination of cyclic hypervalent iodine reagents with photoredox catalysts has contributed successfully in organic synthesis. Photoredox catalysis enables various synthetic transformations such as alkynylation, alkenylation, cyanation, amination, cyclization ring expansion reactions under mild reaction conditions. Photoredox catalysis is not limited to inorganic photoredox catalysts but several organic dyes have been used potential as photoredox catalysts. There are few photochemical reactions involving hypervalent iodine reagents have been developed with using photoredox catalysis. This review highlights various photoredox-catalyzed reactions by using hypervalent iodine reagents. Moreover, the photochemical reactions involving hypervalent iodine reagents without using photoredox catalyst are also covered.

\section{Acknowledgements}

Fateh V. Singh is thankful to CSIR New Delhi [Grant No.: 02/(0330)/17-EMR-II] for the financial support.

\section{References}

1. Singh, F. V.; Wirth, T. Comprehensive Organic Chemistry, Knochel, P., 2nd Ed.; Elsevier, 2014, 880-993.

2. Singh, F. V.; Kole, P. B.; Mangaonkar, S. R.; Shetgaonkar, S. E. Beilstein J. Org. Chem. 2018, 14, $1778-1805$. https://doi.org/10.3762/bjoc.14.152

3. Silva, L. F.; Olofsson, B. Nat. Prod. Rep., 2011, 28, 1722-1754.

https://doi.org/10.1039/C1NP00028D

4. Maertens, G.; L'Homme, C.; Canesi, S.; Front. Chem., 2015, 2, 1-19. DOI:

https://doi.org/10.3389/fchem.2014.00115

5. Zhdankin, V. V.; Stang, P. J. Chem. Rev. 2008, 108, 5299-5358. 
https://doi.org/10.1021/cr800332c

6. Zhdankin, V. V. Arkivoc 2009, 1, 1-62.

https://doi.org/10.3998/ark.5550190.0010.101

7. Farooq, U.; Shah, A. A.; Wirth, T. Angew. Chem. 2009, 121, 1036-1038; Angew. Chem. Int. Ed. 2009, 48, 1018-1020.

https://doi.org/10.1002/anie.200805027

8. Zhdankin, V. V. J. Org. Chem. 2011, 76, 1185-1197.

https://doi.org/10.1021/jo1024738

9. Merritt, E. A.; Olofsson, B. Angew. Chem. 2009, 121, 9214-9234; Angew. Chem. Int. Ed. 2009, 48, 90529070.

https://doi.org/10.1002/anie.200904689

10. Yoshimura, A.; Zhdankin, V. V. Chem. Rev. 2016, 116, 3328-3435. https://doi.org/10.1021/acs.chemrev.5b00547

11. Liang, H.; Ciufolini, M. A. Tetrahedron 2010, 66, 5884-5892.

https://doi.org/10.1016/j.tet.2010.05.020

12. Qurban, J.; Elsherbini, M.; Alharbi, H.; Wirth, T. Chem. Commun. 2019, 55, 7998-8000. DOI: https://pubs.rsc.org/en/content/articlelanding/2019/CC/C9CC03905H\#!divAbstract

13. Hokamp, T.; Wirth, T.J. Org. Chem. 2019, 84, 8674-8682. DOI: https://pubs.acs.org/doi/10.1021/acs.joc.9b01315

14. Elsherbini, M.; Winterson, B.; Alharbi, H.; Folgueiras-Amador, A. A.; Génot, C.; Wirth, T. Angew. Chem. Int. Ed. 2019, 58, 9811-9815.

https://onlinelibrary.wiley.com/doi/abs/10.1002/anie.201904379

15. Zhdankin, V.V. Arkivoc 2020, (iv), 1-11.

https://doi.org/10.24820/ark.5550190.p011.145

16. Tinnis, F.; Stridfeldt, E.; Lundberg, H.; Adolfsson, H.; Olofsson, B. Org. Lett. 2015, $17,2688-2691$. https://doi.org/doi:10.1021/acs.orglett.5b01079

17. Ghosh, R.; Stridfeldt, E.; Olofsson, B. Chem. Eur. J. 2014, 20, 8888-8892.

https://doi.org/10.1002/chem.201403523

18. Uyanik, M.; Ishihara, K. Chem. Commun. 2009, 2086-2099.

https://doi.org/10.1039/B823399C

19. Guérard, K. C.; Sabot, C.; Beaulieu, M.-A.; Giroux, M. A.; Canesi, S. Tetrahedron 2010, 66, 5893-5901. https://doi.org/10.1016/j.tet.2010.03.096

20. Singh, F. V.; Wirth, T. Org. Lett. 2011, 13, 6504-6507.

https://doi.org/10.1021/ol202800k

21. Mangaonkar, S. R.; Kole, P. B.; Singh, F. V. Synlett 2018, 29,199-202.

https://doi.org/10.1055/s-0036-1588575

22. Yusubov, M. S.; Soldatova, N. S.; Postnikov, P.; Valiev, R. R.; Yoshimura, A.; Wirth, T.; Nemykin, V.; Zhdankin, V. V. Chem. Commun. 2019, 55, 7760-7763.

https://doi.org/10.1039/C9CC04203B

23. Yusubov, M.S.; Postnikov, P.S.; Yoshimura, A.; Zhdankin, V.V. Synlett 2020, 31, 315-326. https://doi.org/10.1055/s-0039-1690761

24. Wang, H.; Fan, R. J. Org. Chem. 2010, 75, 6994-6997. https://doi.org/10.1021/jo1014245 
25. Du, X.; Chen, H.; Chen, Y.; Chen, J.; Liu, Y. Synlett 2011, 1010-1014.

https://doi.org/10.1055/s-0030-1259717

26. Singh, F. V.; Wirth, T. Synthesis 2012, 44, 1171-1177.

https://doi.org/10.1055/s-0031-1290588

27. Singh, F. V.; Mangaonkar, S. R. Synthesis, 2018, 50, 4940-4948.

https://doi.org/10.1055/s-0037-1610650

28. Singh, F. V.; Mangaonkar, S. R.; Kole, P. B. Synth. Commun., 2018, 48, 2169-2176. DOI:

https://doi.org/10.1080/00397911.2018.1479760

29. Budhwan, R.; Garg, G.; Namboothiri, I. N. N.; Murarka, S. Targets Heterocycl. Syst. 2019, 23, 27-52.

30. Mangaonkar, S. R.; Singh, F. V. Synthesis, 2019, 51, 4473-4476.

https://doi.org/10.1055/s-0039-1690621

31. Mizar, P.; Burrelli, A.; Günther, E.; Söftje, M.; Farooq, U.; Wirth, T. Chem. Eur. J. 2014, 20, $13113-13116$. https://doi.org/10.1002/chem.201404762

32. Yoshimura, A.; Koski, S. R.; Fuchs, J. M.; Saito, A.; Nemykin, V. N.; Zhdankin, V. V. Chem. Eur. J. 2015, 21, 5328-5331.

https://doi.org/10.1002/chem.201500335

33. Mizar, P.; Niebuhr, R.; Hutchings, M.; Farooq, U.; Wirth, T. Chem. Eur. J. 2016, $22,1614-1617$. https://doi.org/10.1002/chem.201504636

34. Kandimalla, S. R.; Parvathaneni, S. P.; Sabitha, G.; Reddy, B. V. S. Eur. J. Org. Chem. 2019, 1687-1714.

35. Tinnis, F.; Stridfeldt, E.; Lundberg, H.; Adolfsson, H.; Olofsson, B. Org. Lett. 2015, 17, $2688-2691$. https://doi.org/10.1021/acs.orglett.5b01079

36. Ghosh, R.; Stridfeldt, E.; Olofsson, B. Chem. Eur. J. 2014, 20, 8888-8892. https://doi.org/10.1002/chem.201403523

37. Ghosh, R.; Lindstedt, E.; Jalalian, N.; Olofsson, B. ChemistryOpen 2014, 3, 54-57. https://doi.org/10.1002/open.201402006

38. Brown, M.; Delorme, M.; Malmedy, F.; Malmgren, J.; Olofsson, B.; Wirth, T. Synlett 2015, 26, $1573-1577$. https://doi.org/10.1055/s-0034-1380687

39. Lindstedt, E.; Stridfeldt, E.; Olofsson, B. Org. Lett. 2016, 18, 4234-4237. DOI: https://pubs.acs.org/doi/abs/10.1021/acs.orglett.6b01975

40. Villo, P.; Kervefors, G.; Olofsson, B. Chem. Commun. 2018, 54, 8810-8813. DOI: https://doi.org/10.1039/C8CC04795B

41. Purkait, N.; Kervefors, G.; Linde, E.; Olofsson, B. Angew. Chem. Int. Ed. 2018, 57, 11427-11431. DOI: https://doi.org/10.1002/anie.201807001

42. Parra, A.; Reboredo, S. Chem. Eur. J. 2013, 19, 17244-17260.

https://doi.org/10.1002/chem.201302220

43. Baba, T.; Takahashi, S.; Kambara, Y.; Yoshimura, A.; Nemykin, V.N.; Zhdankin, V.V.; Saito, A. Adv. Synth. Cat. 2017, 359, 3860-3864.

https://doi.org/10.1002/adsc.201700934

44. Yoshimura, A.; Jarvi, M.E.; Shea, M.T.; Makitalo, C.L.; Rohde, G.T.; Yusubov, M.S.; Saito, A.; Zhdankin, V.V. Eur. J. Org. Chem. 2019, 6682-6689.

https://doi.org/10.1002/ejoc.201901258

45. Yoshimura, A.; Saito, A.; Yusubov, M.S.; Zhdankin, V.V. Synthesis 2020, 52, 2299-2310.

https://doi.org/10.1055/s-0040-1707122 
46. Singh, F. V.; Wirth, T. Synthesis 2013, 45, 2499-2511 and references are cited therein. https://doi.org/10.1055/s-0033-1339679

47. Brown, M.; Kumar, R.; Rehbein J.; Wirth, T. Chem. Eur. J. 2016, 22, 4030-4035. https://doi.org/10.1002/chem.201504844

48. Malmedy, F.; Wirth, T. Chem. Eur. J. 2016, 22, 16072-16077. https://doi.org/10.1002/chem.201684562

49. Shetgaonkar, S. E.; Krishnan, M.; Singh, F. V. Mini-Rev. Org. Chem. 2020, in press. DOI: 10.2174/1570193X17999200727204349

50. Richardson, R. D.; Wirth, T. Angew. Chem. Int. Ed. 2006, 45, 4402-4404. DOI: https://doi.org/10.1002/anie.200601817

51. Singh, F. V.; Wirth, T. Chem. Asian J. 2014, 9, 950-971.

https://doi.org/10.1002/asia.201301582

52. Li, X.; Chen, P.; Liu, G. Beilstein J. Org. Chem. 2018, 14, 1813-1825.

53. Parra, A. Chem. Rev. 2019, 119, 24, 12033-12088.

https://doi.org/10.1021/acs.chemrev.9b00338

54. Flores, A.; Cots, E.; Bergès, J.; Muñiz, K. Adv. Synth. Cat 2019, 361, 2-25. https://doi.org/10.1002/adsc.201800521

55. Wang, L.; Liu, J. Eur. J. Org. Chem. 2016, 1813-1824.

https://doi.org/10.1002/ejoc.201501490

56. Vaillant, F. L.; Waser, J. Chem. Sci. 2019, 10, 8909-8923.

https://doi.org/10.1039/C9SC03033F

57. Waser, J. Top Curr Chem 2016, 373, 187-222.

https://doi.org/10.1007/128 2015 660

58. Wang, Z.; Li, L.; Huang, Y. J. Am. Chem. Soc. 2014, 136, 12233-12236.

https://doi.org/10.1021/ja506352b

59. Wang, H.; Xie, F.; Qi, Z.; Li, X. Org. Lett. 2015, 17, 920-923.

https://doi.org/10.1021/acs.orglett.5b00027

60. Huang, H.; Zhang, G.; Gong, L.; Zhang, S.; Chen, Y.; J. Am. Chem. Soc. 2014, 136, $2280-2283$. https://doi.org/10.1021/ja413208y

61. Huang, H.; Zhang, G.; Chen, Y. Angew. Chem. Int. Ed. 2015, 54, 7872-7876. https://doi.org/10.1002/anie.201502369

62. Tan, H.; Li, H.; Ji, W.; Wang, L. Angew. Chem. Int. Ed. 2015, 54, 8374-8377. https://doi.org/10.1002/anie.201503479

63. Zhou, Q.-Q.; Guo, W.; Ding, W.; Wu, X.; Chen, X.; Lu, L.-Q.; Xiao, W.-J. Angew. Chem. Int. Ed. 2015, 54, 11196-11199.

https://doi.org/10.1002/anie.201504559

64. Vaillant, F. L.; Courant, T.; Waser, J. . Angew. Chem. Int. Ed. 2015, 54, $11200-11204$. https://doi.org/10.1002/anie.201505111

65. Yang, J.; Zhang, J.; Qi, L.; Hu, C.; Chen, Y. Chem. Commun., 2015, 51, 5275-5278. https://doi.org/10.1039/C4CC06344A

66. Yang, C.; Yang, J.-D.; Li, Y.-H.; Li, X.; Cheng, J.-P. J. Org. Chem. 2016, 81, $12357-12363$. https://doi.org/10.1021/acs.joc.6b02385 
67. Garreau, M.; Vaillant, F. L.; Waser, J. Angew. Chem. Int. Ed. 2019, 131, 8266-8270. https://doi.org/10.1002/anie.201901922

68. Mukherjee, S.; Garza-Sanchez, R. A.; Tlahuext-Aca, A.; Glorius, F. Angew. Chem. Int. Ed. 2017, 56, 1472314726.

https://doi.org/10.1002/anie.20170803

69. Jia, K.; Zhang, F.; Huang, H.; Chen, Y. J. Am. Chem. Soc. 2016, 138, $1514-1517$. https://doi.org/10.1021/jacs.5b13066

70. Jia, K.; Pan, Y.; Chen, Y. Angew. Chem. Int. Ed. 2017, 56, $2478-2481$. https://doi.org/10.1002/anie.201611897

71. Jia, K.; Li, J.; Chen, Y. Chem. Eur. J. 2018, 24, 3174-3177.

https://doi.org/10.1002/chem.201800202

72. Vaillant, F. L.; Garreau, M.; Nicolai, S.; Gryn'ova, G.; Corminboeuf, C.; Waser, J. Chem. Sci., 2018, 9, 5883-5889.

https://doi.org/10.1039/C8SC01818A

73. Jiang, H.; Studer, A. Chem. Eur. J. 2019, 25, 516-520.

https://doi.org/10.1002/chem.201805490

74. Morcillo, S. P.; Dauncey, E. M.; Kim, J. H.; Douglas, J. J.; Sheikh, N. S.; Leonori, D. Angew. Chem. Int. Ed. 2018, 57, 12945-12949.

https://doi.org/10.1002/anie.201807941

75. Huang, H.; Jia, K.; Chen, Y. Angew. Chem. Int. Ed. 2015, 54, 1881-11884. https://doi.org/10.1002/anie.201410176

76. Dai, J. J.; Zhang, W.-M.; Shu, Y.-J.; Sun, Y.-Y.; Xu, J.; Feng, Y.-S.; Xu, H.-J. Chem. Commun., 2016, 52, 67936796.

https://doi.org/10.1039/C6CC01530A

77. Vaillant, F. L.; Wodrich, M. D.; Waser, J. Chem. Sci., 2017, 8, 1790-1800. https://doi.org/10.1039/C6SC04907A

78. Li, G.-X.; Morales-Rivera, C. A.; Wang, Y.; Gao, F.; He, G.; Liu, P.; Chen, G. Chem. Sci., 2016, 7, 6407-6412. https://doi.org/10.1039/C6SC02653B

79. Zhang, W.-M.; Dai, J.-J.; Xu, J.; Xu, H.-J. J. Org. Chem. 2017, 82, 2059-2066. https://doi.org/10.1021/acs.joc.6b02891

80. Fearnley, A. F.; An, J.; Jackson, M.; Lindovska, P.; Denton, R. M. Chem. Commun., 2016, 52, 4987-4990. https://doi.org/10.1039/C6CC00556J

81. Liu, N. W.; Liang, S.; Manolikakes, G. Adv. Synth. Catal., 2017, 359, 1308-1319. https://doi.org/10.1002/adsc.201601341

82. Li, D.; Liang, C.; Jiang, Z.; Zhang, J. Z.; Zhuo, W. T.; Zou, F. Y.; Wang, W.-P.; Gao, G. L.; Song, J. J. Org. Chem. 2020, 85, 4, 2733-2742.

https://doi.org/10.1021/acs.joc.9b02933

83. Wang, Z.; Herraiz, A. G.; del Hoyo, A. M.; Suero, M. G. Nature, 2018, 554, 86-91. https://doi.org/10.1038/nature25185

84. Alazet, S.; Preindl, J.; Simonet-Davin, R.; Nicolai, S.; Nanchen, A.; Meyer, T.; Waser, J. J. Org. Chem. 2018, 83, 12334-12356.

https://doi.org/10.1021/acs.joc.8b02068

85. Merino, E.; Nevado, C.; Chem. Soc. Rev. 2014, 43, 6598-6608. 
https://doi.org/10.1039/C4CS00025K

86. Barata-Vallejo, S.; LantaÇo, B.; Postigo, A. Chem. Eur. J., 2014, 20, $16806-16829$. https://doi.org/10.1002/chem.201404005

87. Charpentier, J.; Früh, N.; Togni, A. Chem. Rev. 2015, 115, 650-682.

https://doi.org/10.1021/cr500223h

88. Koike, T.; Akita, M. Top. Catal., 2014, 57, 967-974.

https://doi.org/10.1007/s11244-014-0259-7

89. Pan, X.; Xia, H.; Wu, J. Org. Chem. Front., 2016, 3, 1163-1185.

https://doi.org/10.1039/C6Q000153J

90. Yasu, Y.; Koike, T.; Akita, M.; Angew. Chem. Int. Ed., 2012, 51, 9567-9571. https://doi.org/10.1002/anie.201205071

91. Xu, P.; Xie, J.; Xue, Q.; Pan, C.; Cheng, Y.; Zhu, C. Chem. Eur. J., 2013, 19, $14039-14042$. https://doi.org/10.1002/chem.201302407

92. Yasu, Y.; Koike, T.; Akita, M. Chem. Commun., 2013, 49, 2037-2039.

https://doi.org/10.1039/C3CC39235J

93. Mizuta, S.; Engle, K. M.; Verhoog, S.; Galicia-Lopez, O.; O’Duill, M.; Medebielle, M.; Wheelhouse, K.; Rassias, G.; Thompson, A. L.; Gouverneur, V. Org. Lett., 2013, 15, 6, $1250-1253$. https://doi.org/10.1021/ol400184t

94. Xu, P.; Abdukader, A.; Hu, K.; Chenga, X.; Zhu, C.; Chem. Commun., 2014, 50, $2308-2310$. https://doi.org/10.1039/C3CC48598F

95. Xie, J.; Yuan, X.; Abdukader, A.; Zhu, C.; Ma, J. Org. Lett., 2014, 16, $1768-1771$. https://doi.org/10.1021/ol500469a

96. Carboni, A.; Dagousset, G.; Magnier, E.; Masson, G. Org. Lett., 2014, 16, $1240-1243$. https://doi.org/10.1021/ol500374e

97. Paul, A.; Chatterjee, D.; Rajkamal, Halder, T.; Banerjee, S.; Yadav, S. Tetrahedron Lett. 2015, 56, 2496-2499.

https://doi.org/10.1016/j.tetlet.2015.03.107

98. Martnez, C.; Muñiz, K. Angew. Chem. Int. Ed. 2015, 54, 8287-8291.

https://doi.org/10.1002/anie.201501122

99. Wappes, E. A.; Fosu, S. C.; Chopko, T. C.; Nagib, D. A. Angew. Chem. Int. Ed. 2016, 55, 9974-9978. https://doi.org/10.1002/anie.201604704

100. Ji, W.; Tan, H.; Wang, M.; Li, P.; Wang, L. Chem. Commun., 2016, 52, $1462-1465$. https://doi.org/10.1039/C5CC08253F

101. Chidley, T.; Jameel, I.; Rizwan, S.; Peixoto, P. P.; Pouysegu, L.; Quideau, S.; Hopkins, W. S.; Murphy, G. K. Angew. Chem. Int. Ed. 2019, 58, 16959-16965.

https://doi.org/10.1002/anie.201908994 


\section{Authors' Biographies}

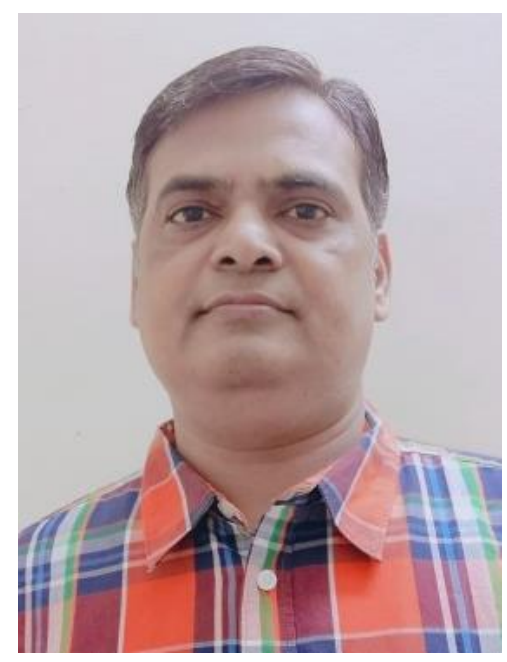

Fateh V Singh has completed his PhD in 2007 with Dr Atul Goel (CSIR-CDRI, Lucknow, India). After the completion of his doctoral studies, he has spent around two years in Prof. H A Stefani's research group at USP, São Paulo, Brazil. In 2010, he joined as Marie Curie postdoctoral fellow with Prof. Thomas Wirth at Cardiff University, UK and worked two years in the area of hypervalent iodine chemistry. He received Dr D S Kothari fellowship in 2013 and worked with Prof. G Mugesh at IISc Bangalore, India for a short stay. In 2014, he started his independent career and joined VIT University, Chennai as an Assistant Professor. Mainly, his research group is interested in the findings of new organoselenium and hypervalent catalysts for organic synthesis. Moreover, his research group is also involved in the development of new organic fluorescent molecules for OLEDs and chemical sensors. Currently, he is having different research grants from Government of India. He has already published more than 50 research papers, several book chapters and review articles.

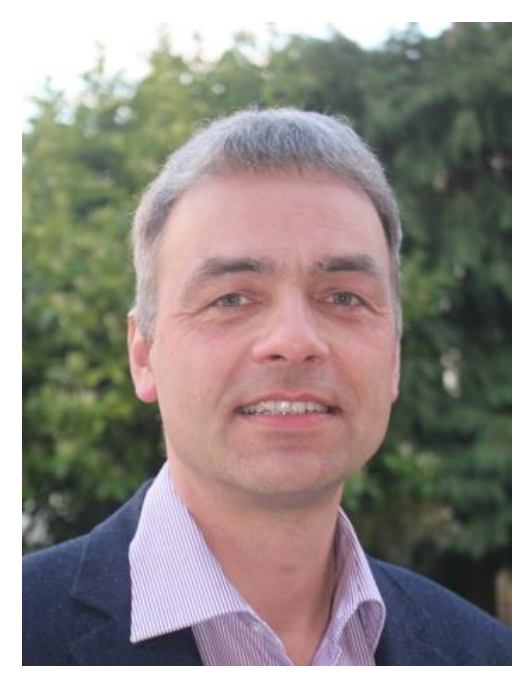

Thomas Wirth is professor of organic chemistry at Cardiff University. After receiving his PhD from TU Berlin, he stayed at Kyoto University as a JSPS fellow. Then he worked independently at the University of Basel before taking up his current position at Cardiff University in 2000. He was awarded the Werner-Prize from the New Swiss Chemical Society, the Wolfson Research Merit Award from the Royal Society and the Bader-Award from the Royal Society of Chemistry. In 2016 he was elected as a fellow of The Learned Society of Wales. His main 
interests of research concern stereoselective electrophilic reactions, oxidative transformations with hypervalent iodine reagents and flow chemistry performed in microreactors.

This paper is an open access article distributed under the terms of the Creative Commons Attribution (CC BY) license (http://creativecommons.org/licenses/by/4.0/) 